\title{
A New Method to Improve the Fracturing Effect of Coal Seams by Using Preset Slots and Induced Stress Shadows
}

\author{
Li Li $\mathbb{D}^{1,2}$ Lei Zhou $\mathbb{D}^{1,2}$ Honglian Li, ${ }^{1,2}$ Binwei Xia,,2 and Junping Zhou ${ }^{1,2}$ \\ ${ }^{1}$ State Key Laboratory of Coal Mine Disaster Dynamics and Control, Chongqing University, Chongqing 400044, China \\ ${ }^{2}$ School of Resources and Safety Engineering, Chongqing University, Chongqing 400030, China \\ Correspondence should be addressed to Lei Zhou; zhoulei84@cqu.edu.cn
}

Received 24 January 2021; Revised 29 March 2021; Accepted 31 March 2021; Published 22 April 2021

Academic Editor: Mohammad Sarmadivaleh

Copyright (C) $2021 \mathrm{Li} \mathrm{Li}$ et al. This is an open access article distributed under the Creative Commons Attribution License, which permits unrestricted use, distribution, and reproduction in any medium, provided the original work is properly cited.

\begin{abstract}
Efficient extraction of coal bed methane before coal mining is essential to eliminate the risk of coal-gas outbursts. However, stimulation technologies should be implemented to enhance the conductivity of the coal seam. In this study, we propose a novel method to create a complex fracture network in underground coal mines with the integration of multiple hydraulic slotting and hydraulic fracturing. In this method, hydraulic slots are used to direct hydraulic fractures and initialize branch fractures, while hydraulic fracturing is used to extend the fractures. Given the mutually exclusive and attractive propagation of multiple fractures, a relatively evenly distributed fracture network can be generated. The results show that (1) the dynamically induced stress shadows of hydraulic fractures can cause exclusive and attractive propagation of multiple hydraulic fractures; (2) a preset slot that deviates from the principal stress can direct hydraulic fractures to a certain extent and generate branch fractures; and (3) with a staggered distribution of preset slots, a relatively large volume of the coal seam in both the minimum and maximum horizontal stress directions can be stimulated, creating a complex fracture network including many vertical branch fractures and a large area of horizontally layered directional fractures.
\end{abstract}

\section{Introduction}

Coal is currently the major primary energy source based on China's basic national conditions, accounting for $58 \%$ of the total energy consumption in 2018 [1], and it will remain at $50 \%$ in 2030 based on the long-term energy strategy. Therefore, efficient and safe mining of coal is a major demand supporting economic development in China. However, coal mining disasters, including roof collapses, coal-gas outbursts, water inrushes, fires, and explosions, frequently restrict efficient coal mining. Among them, China experiences serious gas disasters, which are considered the "first killer" in underground coal mining. A total of 3284 coal mines distributed in 26 main coal production provinces have a high risk of coal-gas outbursts due to their high gas content [2]. Thus, eliminating the risk of coal-gas outbursts in coal mines with high gas content is essential.

Decreasing the content and pressure of methane gas through gas extraction before coal mining has been proven to be a unique measure for preventing coal-gas outbursts.
In Chinese safety regulations, gas pressure under $0.74 \mathrm{MPa}$ and gas content under $6 \mathrm{~m}^{3} / \mathrm{t}$ in coal seams are the preconditions of coal mining [3]. Gas drainage through boreholes was initially used (Figure $1(\mathrm{a})$ ). This method was effective for gas extraction in highly permeable and thick coal seams. However, coal seams in China are generally of low-permeability (from $\mathrm{mD}$ to $\mu \mathrm{D}$, depending on confining stress [4]) and have high gas absorption ratios [5]. Diffusion dominates the gas migration process in the small-scale pores in coal [6]. Therefore, a single drainage borehole has limited effective radius. Thus, a dense distribution of drainage boreholes should be arranged, which is inefficient due to high construction cost.

$\mathrm{Li}$ et al. put forward a novel method to enhance the gas extraction efficiency by creating slots through a pulsed water jet [7]. The circular flat slots (with a radius smaller than $2 \mathrm{~m}$ ) and the induced fractures around the slots provide highly conductive channels for gas drainage; meanwhile, the stress relief around the slots is advantageous for gas desorption [8]. This method was further developed by Lu et al. [9] and Lin et al. [10], in which long cross boreholes drilled from 


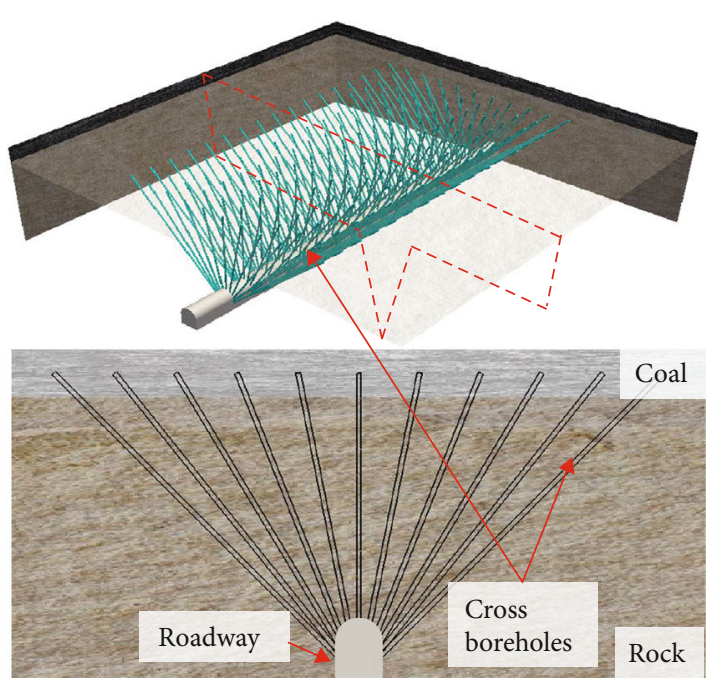

(a) Cross boreholes

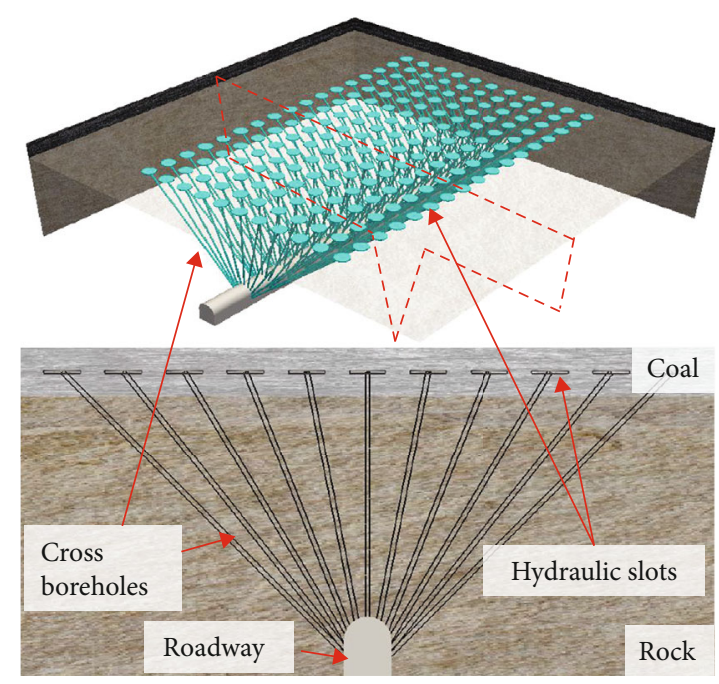

(b) Cross boreholes + hydraulic slots

FIGURE 1: Illustration of methane extraction by (a) dense cross boreholes and (b) cross boreholes + hydraulic slots.

hard rock stratum to a coal seam combined with hydraulic slots were used for gas extraction (Figure 1(b)). According to field experience [11], the gas extraction efficiency after hydraulic slotting was proven to be several times greater than that by borehole drainage at the initial stage. Although hydraulic slotting has shown great benefit, the effective radius along the coal seam was found to be no more than $2.5 \mathrm{~m} \mathrm{[12];}$ meanwhile, the stress concentrated at the tips around the slots, which reduces the permeability and prevents gas migration from the coal seam to the slots [13].

Hydraulic fracturing is considered a reliable reservoir stimulation technic and is extensively utilized in the oil and gas industry [14]. Nowadays, it has also been adopted for permeability enhancement in coal seams [15], as the disturbed volume of a hydraulic fracture is significantly greater than that of a hydraulic slot. Prior experimental [16-19] and numerical studies [20-22] of hydraulic fracturing application in coal revealed that a fracture network with high complexity can be created by hydraulic fracturing, forming T-shaped, Zshaped, $\mathrm{H}$-shaped, \pm -shaped, and \#-shaped patterns that are mainly controlled by stress conditions, preexisting natural discontinuities (soft interlayers, bedding planes, and cleats) and their orientations, rock properties, operational parameters (injection rate, injection volume, and fluid viscosity), etc. Among these factors, stress dominates the major direction of fracture propagation and the complexity of the hydraulic fracture network, and in cases under high stress anisotropy conditions, merely a typical single long hydraulic fracture can be created. As a result, a large unstimulated zone exists between hydraulic fractures, which involves the risk of coal-gas outbursts. Therefore, the main challenge of hydraulic fracturing applications in a coal seam is overcoming the in situ stress restriction effect on the fracture propagation to generate more fractures.

Directional hydraulic fracturing by the use of preset slots has been proposed and experimentally studied by several scholars [23-25]. In these studies, artificial flat slots with a certain orientation deviating from the principal stress direc- tion were created around the injection borehole. During the fluid injection, hydraulic fractures were first initialized at the tips of the slots and in the direction parallel to the slots. Then, the fractures gradually deflected responding to the minimum principal stress (both directions are orthogonal). The directional deflection of the fractures depended on the stress anisotropy, slot length, deviation angle, injection rate, etc. In the case of low stress anisotropy, the planes of the hydraulic fractures and the preset slots can be coincided without deflecting. In cases with high stress anisotropy and high deviation angles, fractures can split into branch fractures. Presuming this principle, Liu et al. [26] and Yan et al. [27] conducted 2D numerical studies on directional hydraulic fracturing technology with preset slots on an engineering scale. The feasibility of this technology to reorient hydraulic fractures was verified. However, they considered only the stress condition with minimum principal stress in the vertical direction, which accounts for the smallest proportion (6\%) in China and appears mainly in relatively shallow coal seams [28]. In most cases, the vertical stress plays the role of the intermediate or the maximum principal stress, particularly with increased depth. In addition, the results of 2D numerical simulations have limited field applications.

The generation of stress shadows is another possible measure that can be used to reorient hydraulic fractures. A stress shadow is defined as changes in the stress magnitude and orientation around a hydraulic fracture [29]. In general, stress increases in the nearby region of the pressurized fracture along the normal direction of its plane and decreases simultaneously around the tip region of the fracture [30]. The extent of the stress shadow is related to the fracture pattern, the internal fluid pressure, the in situ stress, the mechanical properties of the rock formation, etc. When another hydraulic fracture penetrates the stress shadow region of this fracture, it may be deflected or cease propagating. A good example is the competitive propagation of hydraulic fractures initialized at different stages and different clusters in horizontal wells [31,32]. Different propagation patterns of 
multiple fractures (exclusive mode or attractive mode) can be attained mutually, owing to the temporal stress shadow effect which has a significant impact on approaching hydraulic fractures by affecting its propagation direction. To the best of our knowledge, limited studies have been conducted on stress shadows as a positive measure to reorient hydraulic fractures.

This paper is aimed at enhancing methane-extraction efficiency in underground coal mines (with the stress condition $\sigma_{v}>\sigma_{h}$ ), and we present a novel method to create a complex fracture network with the integration of multiple preset slots and hydraulic fracturing. In this method, hydraulic slots are used to direct slot fractures and to initialize branch fractures around the injection slot, while hydraulic fracturing is used to extend the fractures to a large volume. Due to the mutually exclusive and attractive propagation of multiple fractures, a relatively evenly distributed fracture network can be generated. The theoretical principle of this method is introduced in detail, including the generation and reorientation of branch fractures through preset slots and induced stress shadows. Based on the theoretical analyses, a threedimensional numerical tool with reliable performance in modelling multiple hydraulic fracture propagation is used to simulate the proposed technology on the field scale. According to the numerical study, the feasibility of the proposed method is evaluated and verified. Meanwhile, suggestions and limitations regarding field applications are provided.

\section{Analysis of the Stress Field around a Pressurized Fracture}

Two criteria are required to describe fracture extension: the propagation criterion that determines whether the stress exceeds the strength and the orientation criterion that controls the extension direction. Both criteria are related to the stress magnitude and distribution at the pressurized fracture tip. Therefore, analysing the stress field around the pressurized fracture tip is essential, particularly in cases where the stress field is responding variably to the internal fracture fluid pressure. Figure 2(a) illustrates the loading conditions on a rock mass containing a single fracture with arbitrary orientation that deviates from the principal stress direction. The stress distribution of this problem was comprehensively studied at the beginning of the last century. To analytically solve the stress distribution, a Cartesian coordinate system is used, in which the $x$-axis is set parallel to the fracture (Figure 2(b)). The coordinate stress can be converted from the principal stress through tensor transformation:

$$
\left\{\begin{array}{l}
q_{x}=\sigma_{3} \cos ^{2} \alpha+\sigma_{1} \sin ^{2} \alpha, \\
q_{y}=\sigma_{3} \sin ^{2} \alpha+\sigma_{1} \cos ^{2} \alpha, \\
q_{x y}=\sigma_{1} \sin \alpha \cos \alpha-\sigma_{3} \cos \alpha \sin \alpha,
\end{array}\right.
$$

where $q_{x}$ and $q_{y}$ are the normal stresses on the fracture $(\mathrm{MPa}) ; \sigma_{1}$ and $\sigma_{3}$ are the principal stresses on the calculation element (MPa); $q_{x y}$ is the shear stress on the fracture (MPa); and $\alpha$ is the deviation angle between the Cartesian local coordinate and the principal stress coordinate $\left({ }^{\circ}\right)$.

According to the superposition principle in elasticity theory [33], complex loading conditions can be divided into the superposition of three independent loading conditions. These conditions are normal and shear stresses on the outer boundary of the rock mass and internal fluid pressure on the fracture boundary (Figure 2(c)). The fracture can be considered a degenerate ellipse with an infinite axial ratio. Analytical stress solutions around the fracture tip for each case are obtained in $[29,34]$ and can be added together (equation (2)). The maximum circumferential tensile stress (relatively minimum principal stress according to principle of effective stress) criterion can be used to describe the extension direction of a fracture, in which no shear stress remains [35]. According to equations (1) and (2), the fracture extension direction is clearly dependent on the in situ stress, the internal fluid pressure, the length of the fracture, and the deviation angle of the fracture from the principal stress direction.

$$
\begin{aligned}
& \sigma_{x}=q_{y} \sqrt{\frac{c}{2 r_{1}}} \cos \frac{\theta_{1}}{2}\left(1-\sin \frac{\theta_{1}}{2} \sin \frac{3 \theta_{1}}{2}\right)-q_{x y} \sqrt{\frac{c}{2 r_{1}}} \sin \frac{\theta_{1}}{2}\left(2+\cos \frac{\theta_{1}}{2} \cos \frac{3 \theta_{1}}{2}\right)+P_{f}\left(\frac{r}{\sqrt{r_{1} r_{2}}} \cos \left(\theta-\frac{\theta_{1}+\theta_{2}}{2}\right)-1+\frac{r}{c}\left(\frac{c^{2}}{r_{1} r_{2}}\right) \sin ^{3 / 2} \sin \frac{3}{2}\left(\theta_{1}+\theta_{2}\right)\right), \\
& \sigma_{y}=q_{y} \sqrt{\frac{c}{2 r_{1}}} \cos \frac{\theta_{1}}{2}\left(1+\sin \frac{\theta_{1}}{2} \sin \frac{3 \theta_{1}}{2}\right)+q_{x y} \sqrt{\frac{c}{2 r_{1}}} \sin \frac{\theta_{1}}{2} \cos \frac{\theta_{1}}{2} \cos \frac{3 \theta_{1}}{2}+P_{f}\left(\frac{r}{\sqrt{r_{1} r_{2}}} \cos \left(\theta-\frac{\theta_{1}+\theta_{2}}{2}\right)-1+\frac{r}{c}\left(\frac{c^{2}}{r_{1} r_{2}}\right)^{3 / 2} \sin \theta \sin \frac{3}{2}\left(\theta_{1}+\theta_{2}\right)\right), \\
& \text { influence of fluid pressure } \\
& \sigma_{x y}=q_{y} \sqrt{\frac{c}{2 r_{1}}} \sin \frac{\theta_{1}}{2} \cos \frac{\theta_{1}}{2} \cos \frac{3 \theta_{1}}{2}+q_{x y} \sqrt{\frac{c}{2 r_{1}}} \cos \frac{\theta_{1}}{2}\left(1-\sin \frac{\theta_{1}}{2} \sin \frac{3 \theta_{1}}{2}\right)-P_{f} \frac{r}{c}\left(\frac{c^{2}}{r_{1} r_{2}}\right)^{3 / 2} \sin \theta \cos \frac{3}{2}\left(\theta_{1}+\theta_{2}\right),
\end{aligned}
$$

where $q$ is the boundary stress that can be converted from the principal stress (equation (1)) $(\mathrm{MPa}) ; P_{f}$ is internal pressure acting on the fracture surface (MPa); and $c, \theta$, and $r$ are the geometric parameters that are defined in Figure 2(c).
Figure 3 shows an example with three numerical simulation stress distributions around a pressurized fracture; this example visually provides the change in stress magnitude and direction (stress shadow) under different stress conditions. 


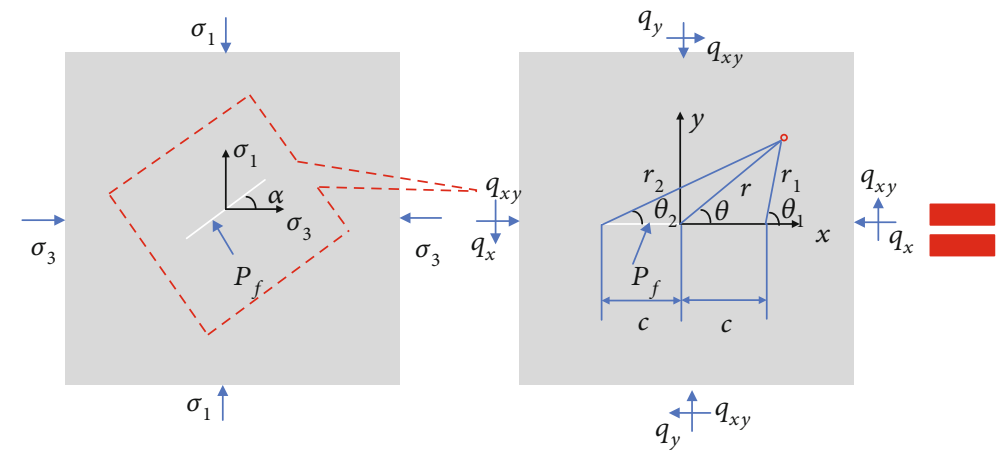

(a)

(b)

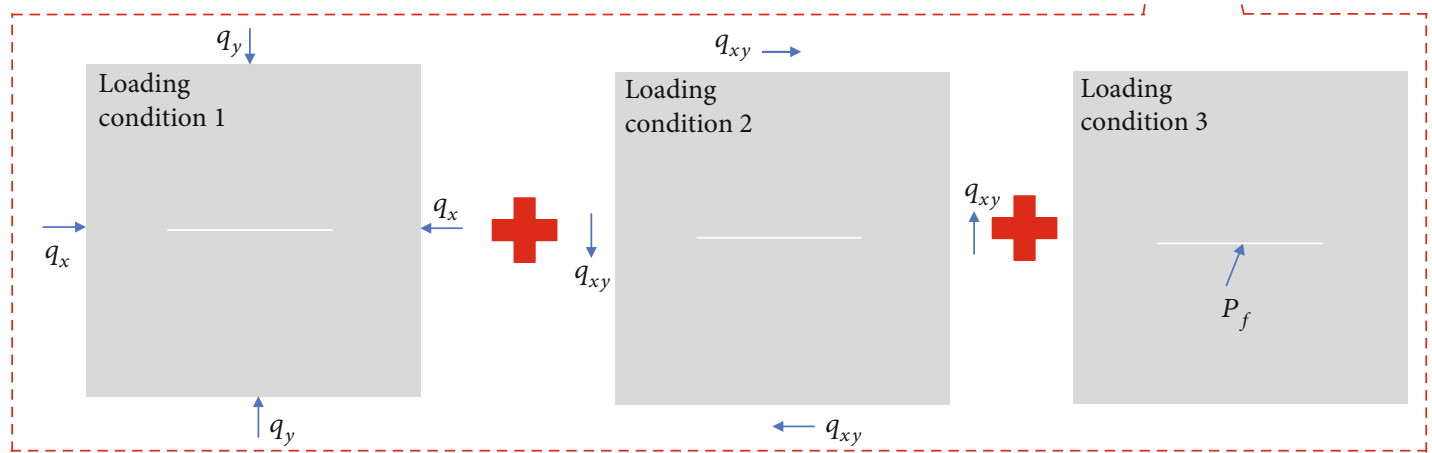

(c)

FIGURE 2: Illustration of the loading conditions on a rock mass containing a single fracture.

In all three cases, the fluid pressure $(15 \mathrm{MPa})$ is three times the initial minimum principal stress $(5 \mathrm{MPa})$, which corresponds to the case in hydraulic fracturing. The maximum principal stress is set at $5 \mathrm{MPa}, 10 \mathrm{MPa}$, and $20 \mathrm{MPa}$, respectively. A preset fracture is arranged in the middle of the model with a deviation angle of $45^{\circ}$ from the principal stress direction. According to Figure 3, the stress clearly increases in the nearby region of the pressurized fracture along the normal direction of its plane and decreases simultaneously around the tip region of the fracture, which confirms a previous statement [30]. However, the pattern of the stress distribution changes from symmetric to antisymmetric as the stress anisotropy (the ratio of the minimum to the maximum stress) increases.

The stress orientation is also affected by the internal fluid pressure of the deviating preset fracture. In 2D cases, the fracture propagation direction can be seen as the direction that coincides with the maximum principal stress. When the fluid pressure in the fracture is significantly greater than the maximum principal stress (case 1 in Figure 3(a)), the propagation direction at its tip can remain in the initial orientation of the preset fracture, indicating that the preset fracture works well to direct the fracture propagation. Meanwhile, the stress directions in other regions around the preset fracture significantly change; in particular, they are reoriented to be orthogonal to the preset fracture. The impact of the fluid pressure on the stress reorientation shows positive correlation with the ratio of the fluid pressure and the maximum principal stress. In a con- trary situation where the internal fluid pressure is smaller than the maximum principal stress (case 3 in Figure 3(c)), the original stress direction becomes the dominant factor. In summary, the propagation reorientation effect by a preset fracture is influenced by the deviation angle, the fluid pressure, and the in situ stress, and it can be basically categorized as controlled by fluid pressure, by both fluid pressure and stress, or by stress. In addition, when multiple fractures propagate, the change in the stress direction caused by one fracture may change the propagation directions of other fractures. The phenomenon of competitive propagation when multiple fractures exist concurrently is discussed in the next section.

\section{Reorientation of Hydraulic Fractures by Use of Preset Slots and Induced Stress Shadows}

According to Section 2, the preset fractures or slots and the stress shadows can change the direction of the primary in situ stress. Thus, these features can be used to reorient hydraulic fractures. Since hydraulic fracture propagation is a dynamic process, the effects of the preset fractures and the stress shadows should be considered from a dynamic point of view. To quantify the dynamic hydraulic fracture propagation under the control of the preset slots and the secondary induced stress shadows, a three-dimensional numerical model developed in a previous study [21] is adopted, which has reliable performance in simulating multiple hydraulic fracture propagation with arbitrary orientation. 


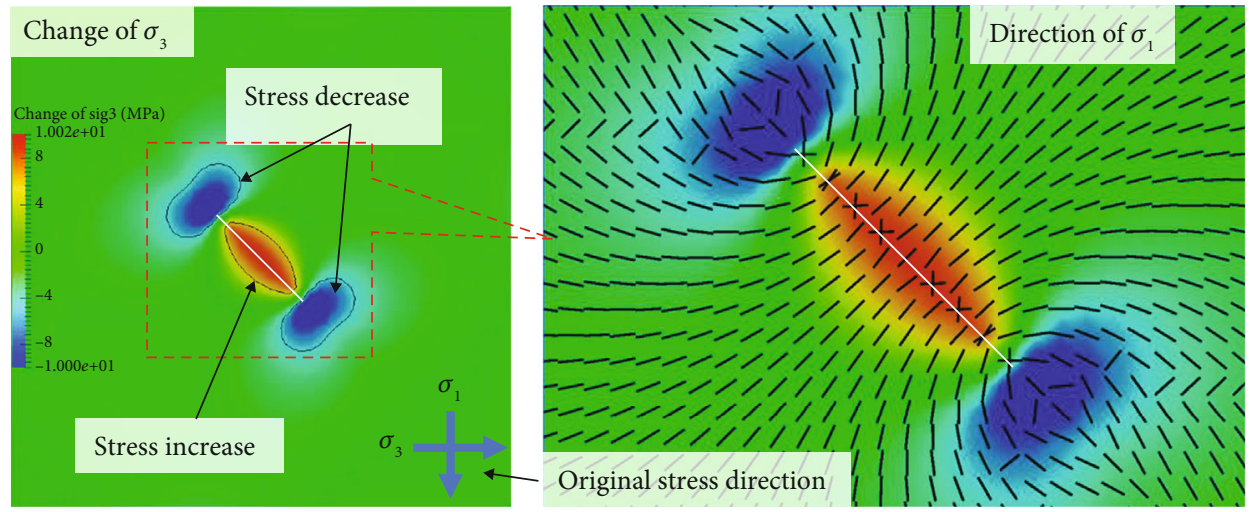

(a) $\sigma_{1}=\sigma_{3}=5 \mathrm{MPa}, P_{f}=15 \mathrm{MPa}$

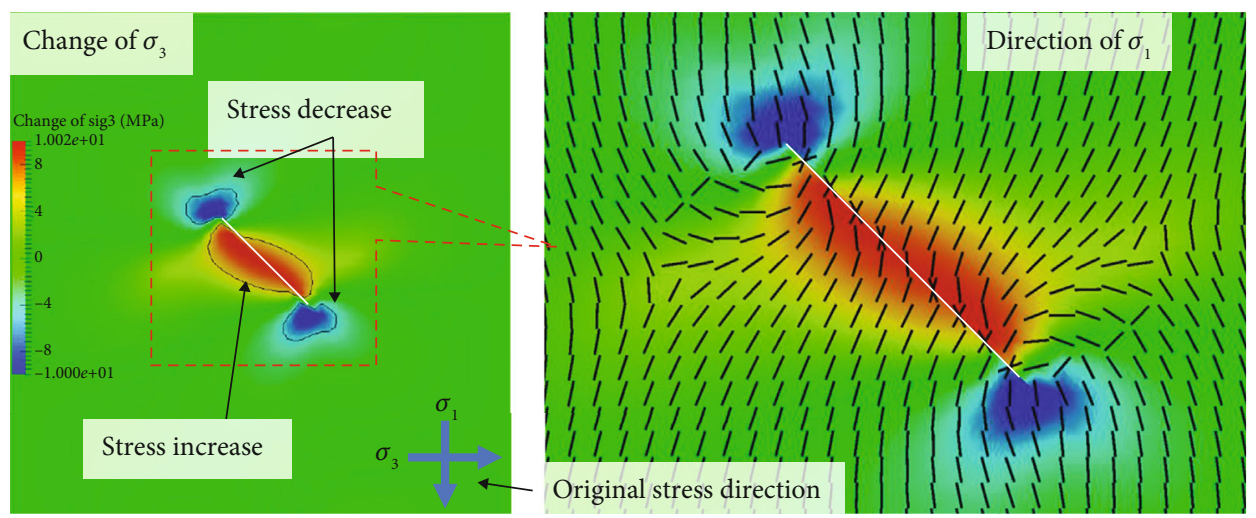

(b) $\sigma_{1}=10 \mathrm{MPa}, \sigma_{3}=5 \mathrm{MPa}, P_{f}=15 \mathrm{MPa}$

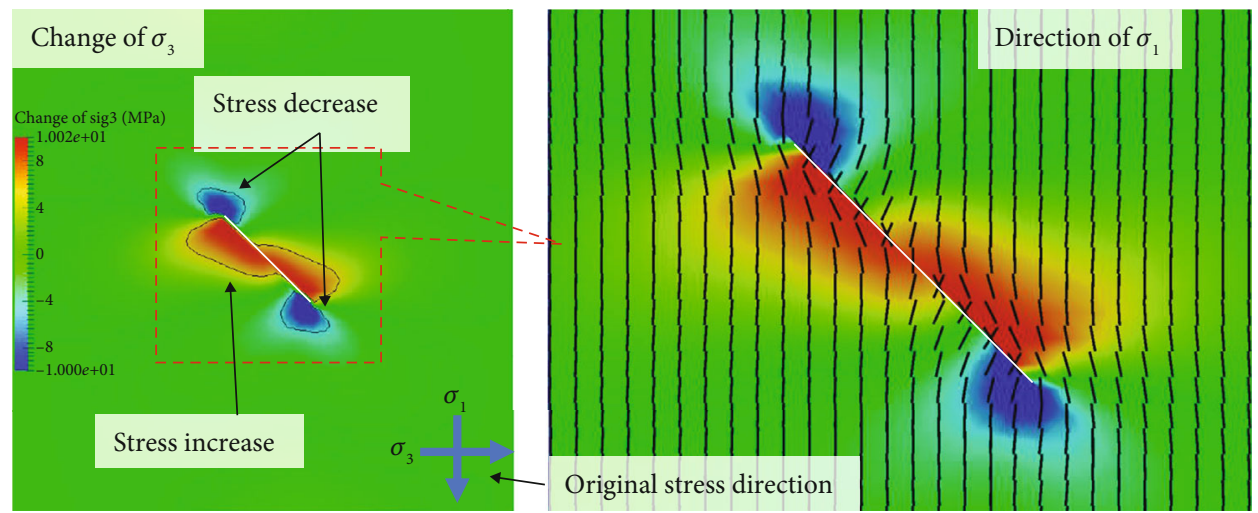

(c) $\sigma_{1}=20 \mathrm{MPa}, \sigma_{3}=5 \mathrm{MPa}, P_{f}=15 \mathrm{MPa}$

FIGURE 3: Stress distribution and orientation around a pressurized fracture under different stress conditions.

The governing equations of the numerical model are briefly described in this section. Then, the reorientation effects of the preset slots and the induced stress shadows are illustrated.

3.1. Governing Equations to Model Spatial Propagation of a Hydraulic Fracture with Arbitrary Orientation. Comprehensive investigations have revealed that complex hydromechanical coupled processes should be considered when analysing hydraulic fracturing behaviours, such as rock deformation with fluid pressure variation, mechanical interaction between multiple crossing fractures, fluid flow in the fracture, fluid leak-off on the fracture surfaces, and fracture propagation. To simplify these complex processes reasonably and considering its low permeability in China's coal reservoirs and that the main concern of this study is fracture spatial propagation and reorientation, fluid leak-off is neglected in this work. To describe the mechanical behaviour, the linear elasticity theory [33] is adopted, and a modification is applied to consider the discontinuum behaviour caused by fractures. A pseudocontinuum concept (separates total deformation of a rock element into deformations of both matrix and fractures) is employed to calculate the deformations (equation (3)), and all the elements are assigned into a fractured rock element 
or an intact rock element, which are of the same scale:

$$
\frac{\partial \boldsymbol{\varepsilon}}{\partial t}=\frac{\partial \boldsymbol{\varepsilon}_{\mathrm{in}}}{\partial t}+\frac{\partial \boldsymbol{\varepsilon}_{f}}{\partial t},
$$

where $\varepsilon, \varepsilon_{\text {in }}$, and $\varepsilon_{f}$ are, respectively, the strain tensor of the rock element, the intact matrix, and the fracture in the matrix form (-).

Considering that a fracture behaves differently in the contact state (elastoplastic strain [32]) and in the open state (elastic strain only [30]), the fracture deformation in different states is computed by a specific fracture constitutive model:

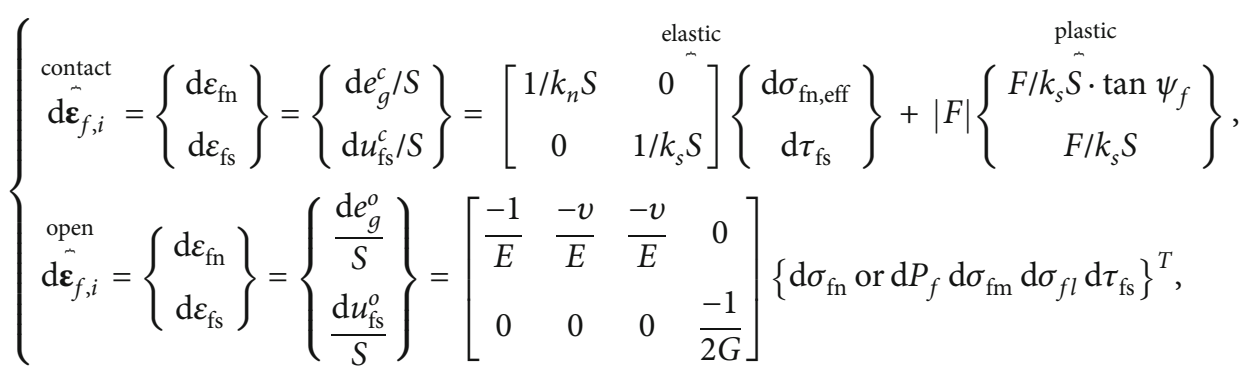

where $n$ and $s$, respectively, represent the normal orientation and the maximum shear orientation on the fracture plane; $e_{g}$ and $u_{f s}$ are, respectively, the fracture aperture $(\mathrm{m})$ and the fracture displacement caused by shear stress $(\mathrm{m}) ; S$ is the fracture spacing $(\mathrm{m})$ and can be simplified as the characteristic length of the calculation element when it only contains one fracture; $k$ is the stiffnesses $(\mathrm{Pa} / \mathrm{m}) ; \sigma_{f n \text {,eff }}$ and $\tau_{f s}$ are, respectively, the effective normal stress $(\mathrm{MPa})$ and the maximum local shear stress $(\mathrm{MPa}) ;|F|$ is a step function with a value of 0 or 1 depending on whether the shear failure function $F$ is negative or not; $\psi_{f}$ is the dilation angle $\left({ }^{\circ}\right) ; v$ is the Poisson's ratio (-); $E$ and $G$ are, respectively, the Young's and the shear modulus $(\mathrm{MPa})$.

$$
F=\tau_{\mathrm{fs}}-\left(C_{f}+\sigma_{\mathrm{fn}, \mathrm{eff}} \tan \phi_{f}\right),
$$

where $C_{f}$ and $\phi_{f}$ represent the cohesion property (MPa) and the friction angle property $\left({ }^{\circ}\right)$ of the fracture.

Meanwhile, Hooke's law (equation (6)) is adopted to calculate the matrix deformation:

$$
\boldsymbol{\varepsilon}_{\text {in }}=\left[\begin{array}{cccccc}
1 / E & -v / E & -v / E & 0 & 0 & 0 \\
-v / E & 1 / E & -v / E & 0 & 0 & 0 \\
-v / E & -v / E & 1 / E & 0 & 0 & 0 \\
0 & 0 & 0 & 1 / 2 G & 0 & 0 \\
0 & 0 & 0 & 0 & 1 / 2 G & 0 \\
0 & 0 & 0 & 0 & 0 & 1 / 2 G
\end{array}\right] \boldsymbol{\sigma}
$$

To compute field variables including the displacement, strain, and stress, both an equilibrium equation (equation (7)) and a geometric equation (equation (8)) are essentially required:

$$
\begin{aligned}
\nabla \boldsymbol{\sigma}+\rho\left(\mathbf{B}-\frac{\partial \mathbf{v}}{\partial t}\right) & =0, \\
\mathrm{~d} \boldsymbol{\varepsilon} & =\frac{1}{2}\left[\nabla(\mathrm{d} \mathbf{u})+\nabla^{T}(\mathrm{~d} \mathbf{u})\right],
\end{aligned}
$$

where $\rho$ represents the density of the rock element $\left(\mathrm{kg} / \mathrm{m}^{3}\right)$, B represents the body force per unit volume in the vector form $\left(\mathrm{m} / \mathrm{s}^{2}\right), \mathbf{v}$ and $\mathbf{u}$ represent the velocity $(\mathrm{m} / \mathrm{s})$ and the displacement $(\mathrm{m})$ in the vector form, respectively.

The fracture is assumed as a lower dimensional (2D) plane. Thus, the cubic flow equation can be adopted to illustrate the average fluid velocity in the pressurized fracture [36]. In addition, a friction factor can be utilized to describe the nonlinear flow characteristic in the fracture. In combination with the mass conservation equation, the pressure conduction equation (equation (9)) is obtained and can be numerically solved. For simplification, the fluid compressibility is neglected since the pressure change caused by the aperture variation is significantly greater than that caused by the density variation:

$$
\frac{\partial e_{g}}{\partial t}+e_{g} q_{s f}+\nabla\left(-\frac{1}{f_{1}} \frac{e_{g}^{2}}{12 \mu} \nabla P_{f}\right)=0,
$$

where $\mu$ represents the viscosity of the injected fluid $(\mathrm{Pa} \cdot \mathrm{s}) ; f_{1}$ represents the friction factor (-); and $q_{s f}$ represents the flow source term $\left(\mathrm{m}^{3} / \mathrm{s}\right)$.

To describe the fracture extension, the orthogonal relationship between the fracture propagation orientation and the minimum principal stress orientation at its tip is assumed. Thus, a tensile stress criterion (equation (10)) mainly considering maximum effective tensile stress is utilized to determine the fracture propagation: 


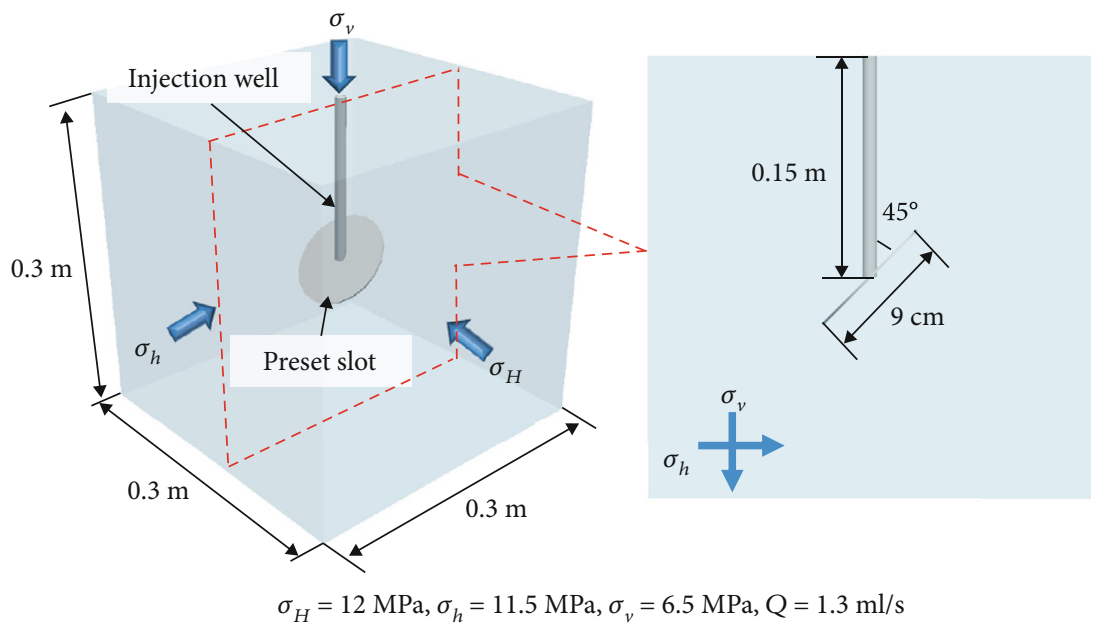

FIgURE 4: Geometric model and conditions in the simulation of lab-scale hydraulic fracture propagation with a preset slot.

$$
\left\{\frac{\left(\sigma_{3}-P_{f}\right)}{\sigma_{t}}\right\}=1 \text {, }
$$

where $\sigma_{3}$ represents the minimum principal stress $(\mathrm{MPa})$ acting on the calculation element and $\sigma_{t}$ represents the tensile strength property $(\mathrm{MPa})$.

To solve those mathematical equations, the sequential coupling method is elaborated and proprietary codes are developed [37]. The fracture presentation method is simultaneously adopted to solve the challenge of tracking a cured $3 \mathrm{D}$ fracture pattern with fixed mesh, in which the fracture is approximately assumed to be a planar polygon in each element [32].

\subsection{Effect of Preset Slots on Hydraulic Fracture Propagation.}

A slot can be considered a fracture. As discussed in Section 2 , preset slots that deviate from the principal stress direction can induce the stress field variation near the slots, affecting the fracture propagation direction. Deng et al. conducted an experimental investigation of directing hydraulic fracturing by the use of a preset slot, which is simulated in this paper to verify the numerical model and to study the effect of the preset slot [24]. An artificial concrete specimen with a cubic dimension of $0.3 \mathrm{~m}$ is used for the hydraulic fracturing test. Figure 4 illustrates the specimen geometry and the test conditions. During preparation of the specimen, a circular slot with a diameter of $9 \mathrm{~cm}$ is embedded and fixed at the centre of the specimen. It forms a $45^{\circ}$ angle with the minimum horizontal stress direction. Fluid is injected at the middle of the slot through a vertical tube. The injection rate is approximately $1.3 \mathrm{ml} / \mathrm{s}$. True triaxial stresses are applied on the specimen, with the minimum principal stress on the top surface. Other parameters, including Young's modulus and fluid viscosity, are adopted from the experimental study (Table 1) [4].

Figure 5 illustrates the simulated hydraulic fracture pattern, which is spatially distorted. The hydraulic fracture is initially directed by the preset slot and then gradually reoriented to the direction perpendicular to the minimum princi-
Table 1: Parameters used in the simulation of lab-scale hydraulic fracture propagation.

\begin{tabular}{lcc}
\hline Material properties & Value & Unit \\
\hline Young's modulus & 8.4 & $\mathrm{GPa}$ \\
Poisson's ratio & 0.23 & - \\
Tensile strength & 2.55 & $\mathrm{MPa}$ \\
Injection rate & 1.3 & $\mathrm{ml} / \mathrm{s}$ \\
Viscosity & 1 & $\mathrm{cP}$ \\
\hline
\end{tabular}

pal stress (vertical stress). The propagation path agrees well with the stress analysis presented in Section 2 and with the experimental observations. According to the results, the numerical model has reliable performance in simulating the spatial hydraulic fracture initiation and propagation with arbitrary orientation. In addition, the preset slot can be concluded to direct the hydraulic fracture within a certain range; however, the primary stress field is still the major factor controlling the fracture propagation, particularly once the fracture tip is away from the slot.

In the field situation, the minimum principal stress generally does not coincide with the vertical stress, especially in coal seams with a large buried depth [28]. In addition, the hydraulic slots are always generated perpendicular to the vertical stress. To analyse the effect of the preset slot under field conditions, the dip angle of the slot is set to zero, and the magnitudes of the vertical and minimum horizontal stresses are exchanged. Other parameters remain unchanged. Figure 6(a) shows the fracture pattern. The hydraulic fracture is first directed by the preset slot in the horizontal direction. Then, a sharp deflection appears due to the horizontal direction of the initial minimum principal stress. As a result, vertical branch fractures are initialized. This phenomenon has also been found in experimental observations [38-40] and 2D numerical results [41, 42] that concern the propagation behaviour of a hydraulic fracture when it encounters interfaces.

The preset slot can be considered a partially cracked or nonpersistent natural fracture. Figure 7 shows the interaction 

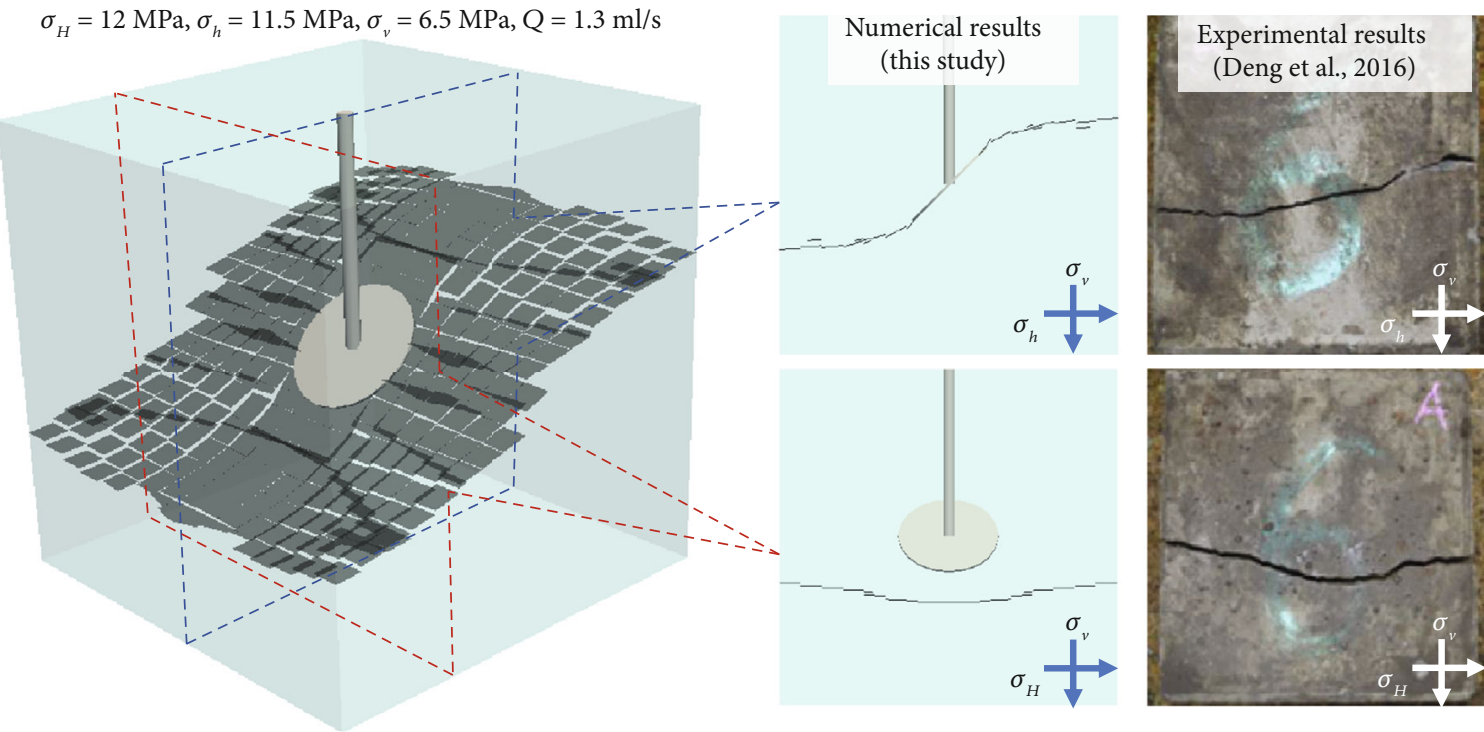

FiguRE 5: Spatial fracture pattern and comparison with experimental results in the simulation of lab-scale hydraulic fracture propagation with a preset slot.

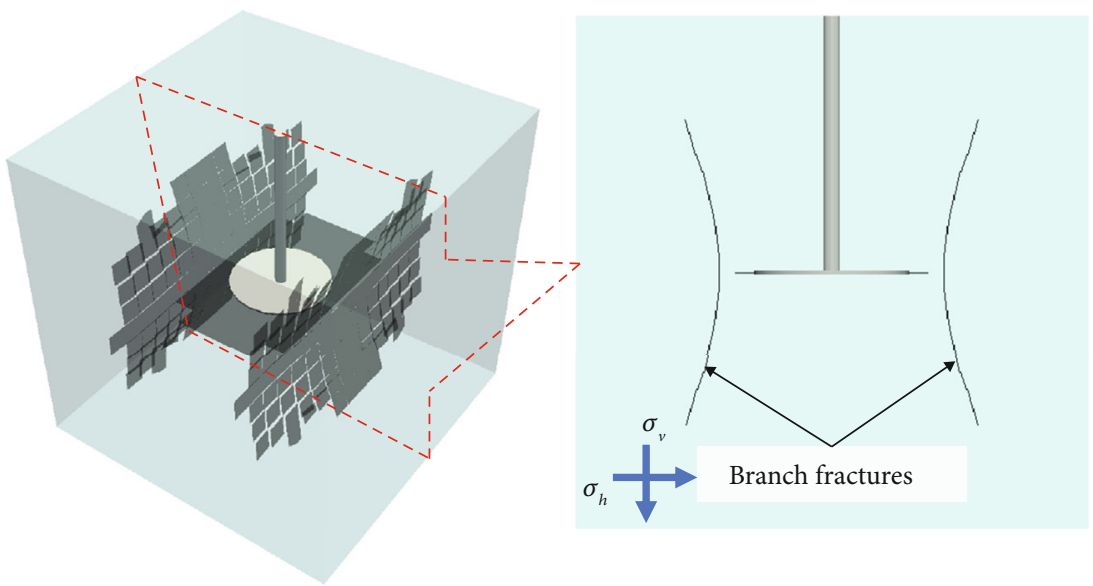

(a) $\sigma_{H}=11.5 \mathrm{MPa}, \sigma_{h}=6.5 \mathrm{MPa}, \sigma_{v}=12 \mathrm{MPa}, Q=1.3 \mathrm{ml} / \mathrm{s}$

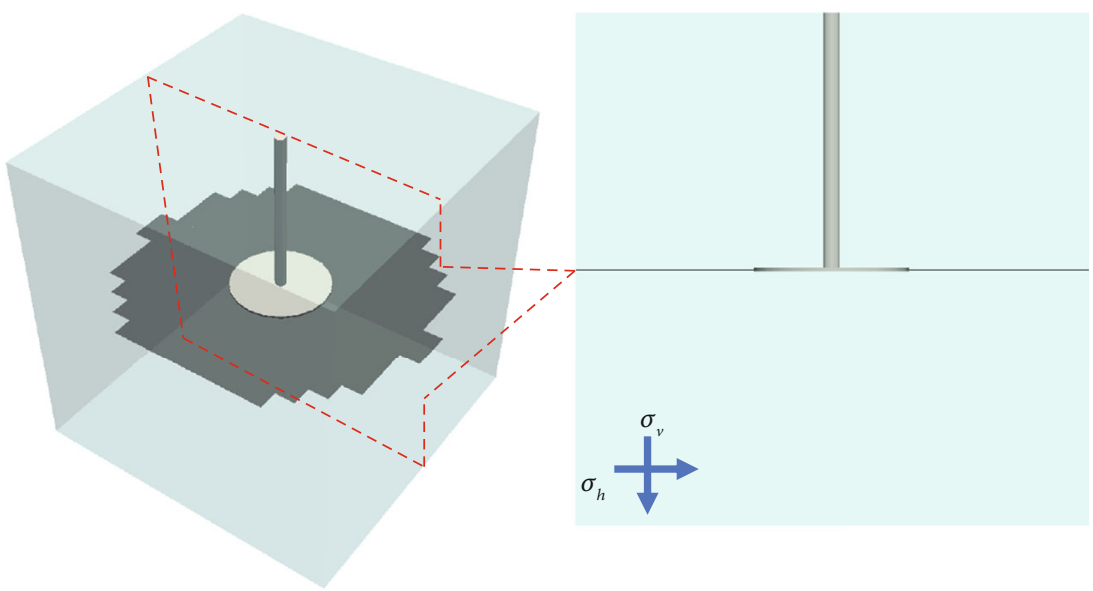

(b) $\sigma_{H}=11.5 \mathrm{MPa}, \sigma_{h}=6.5 \mathrm{MPa}, \sigma_{v}=12 \mathrm{MPa}, Q=13 \mathrm{ml} / \mathrm{s}$

FIGURE 6: Spatial hydraulic fracture patterns under the stress conditions of $\sigma_{H}=11.5 \mathrm{MPa}, \sigma_{h}=6.5 \mathrm{MPa}$, and $\sigma_{v}=12 \mathrm{MPa}$ and injection rates of (a) $1.3 \mathrm{ml} / \mathrm{s}$ and (b) $13 \mathrm{ml} / \mathrm{s}$ in the simulation of lab-scale hydraulic fracture propagation with a preset slot. 

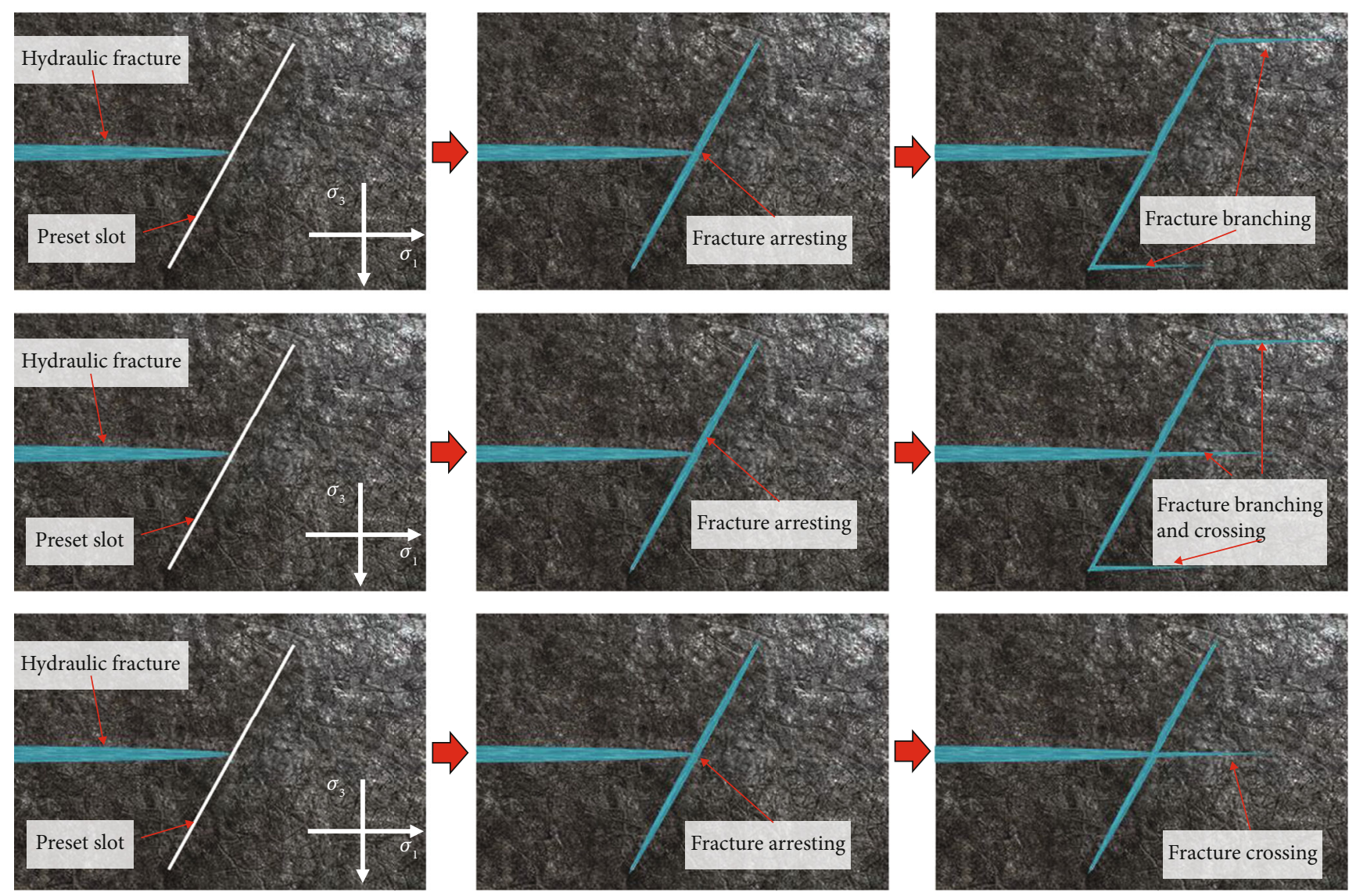

FIGURE 7: Illustrations of the interaction processes between the hydraulic fracture and the preset slot.
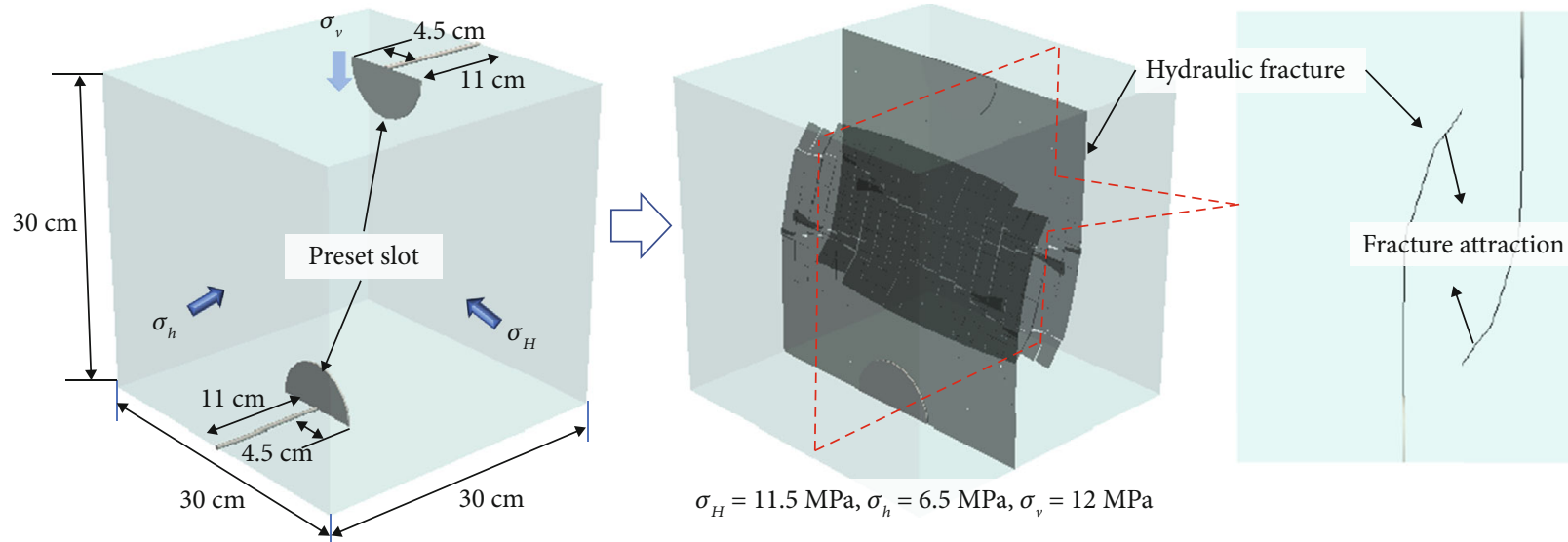

FIGURE 8: Spatial pattern of two oppositely propagating hydraulic fractures.

process between a preset slot and a hydraulic fracture. When the hydraulic fracture approaches the slot, it is first arrested by the preset slot because the preset slot processes high flow conductivity and fluid storage capacity. Later, the void space of the slot is filled by fluid. Three interactions between the preset slot and the hydraulic fracture can be found, including fracture branching, fracture crossing, and both fracture branching and crossing (Figure 7). In general, the branch fractures should be reoriented to an orientation vertical to the minimum principal stress (Figure 6(a)). As discussed in Section 2, the curvature of the reoriented fracture path is determined by the stress anisotropy, the deviation angle of the slot, the length of the preset slot, the injection parameter, etc. In an extreme case, when the preset slot is parallel to the minimum principal stress and the constant injection rate is relatively high, e.g., when the injection rate in this lab-scale simulation is increased 10 times, a planar penny-shaped fracture can be obtained (Figure 6(b)). 


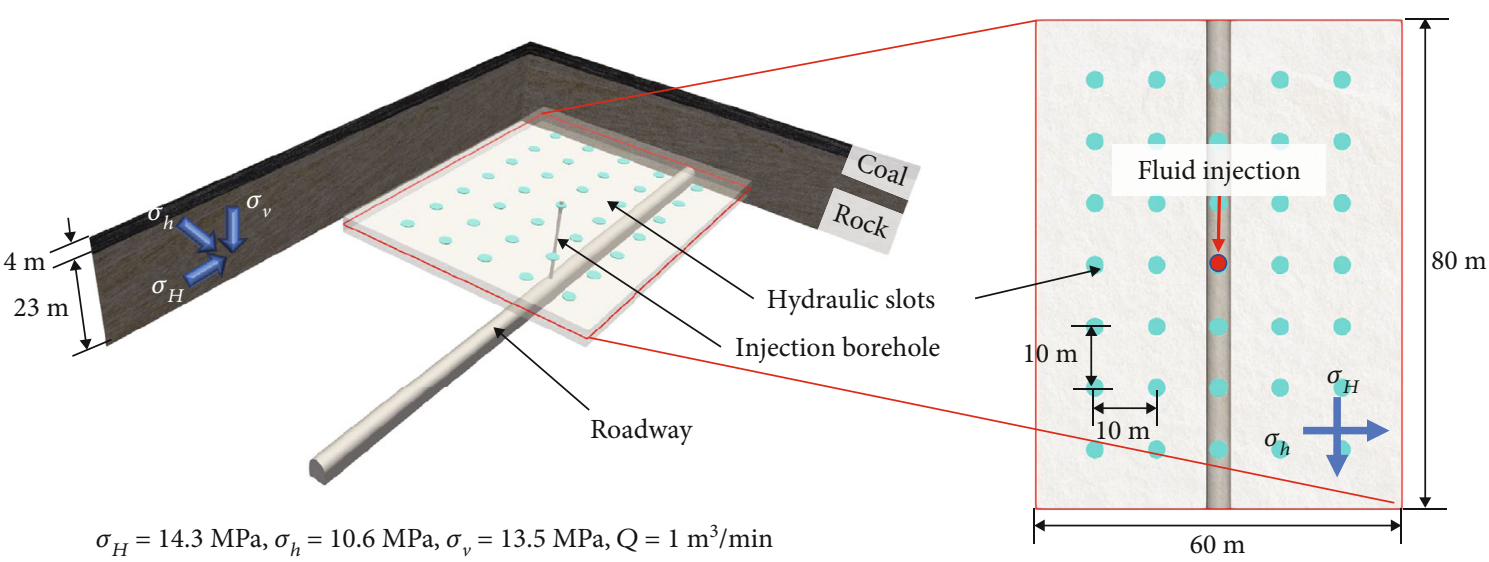

FIGURE 9: Spatial distribution of hydraulic fracturing boreholes in combination with a regular distribution of hydraulic slots.

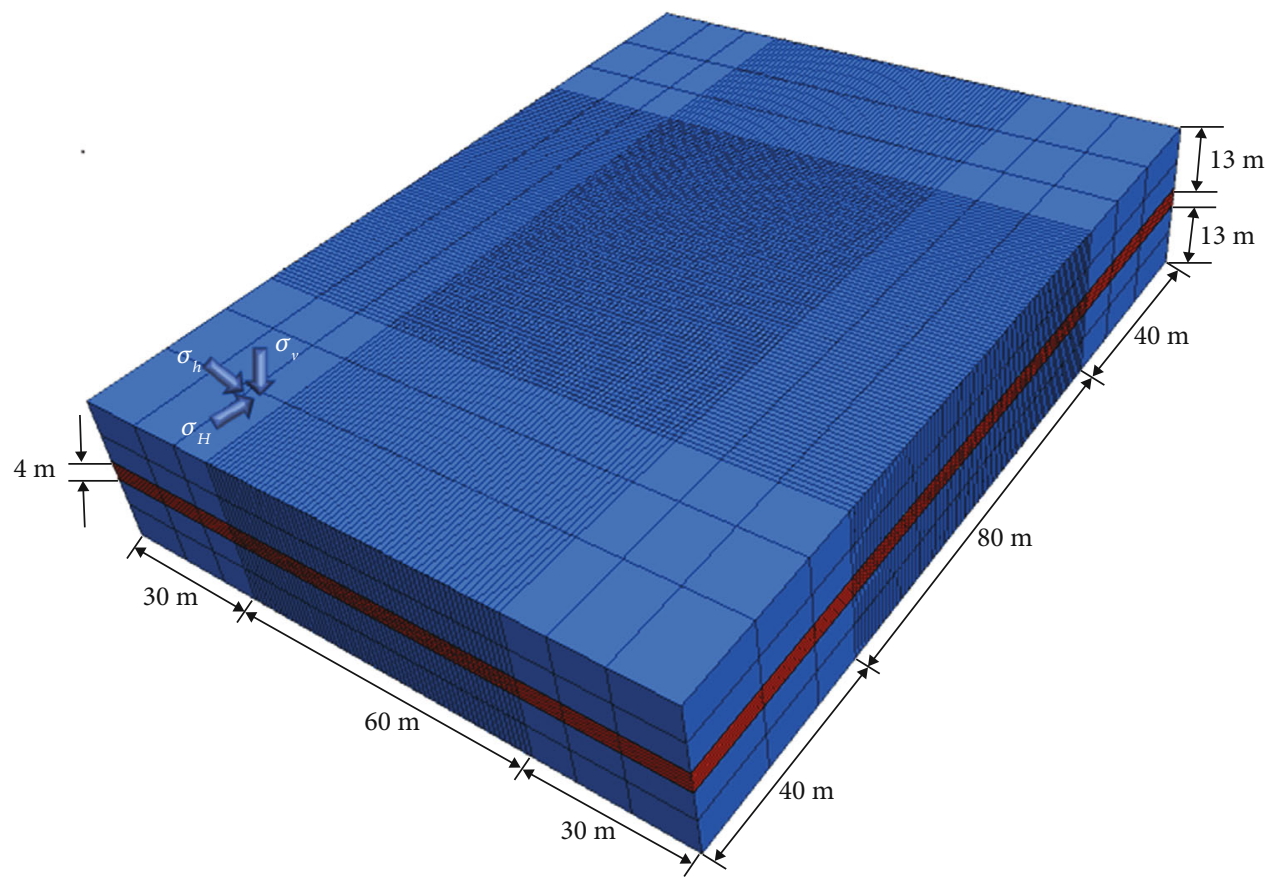

Sandstone reservoir

Coal reservoir

FIGURE 10: Geometric model for simulation of hydraulic fracturing in combination with hydraulic slots.

3.3. Effects of Stress Shadow on Multiple Hydraulic Fracture Propagation. According to previous analysis of a pressurized fracture in Section 2, the stress in the nearby region of the pressurized fracture changes both its magnitude and orientation. This change is defined as a stress shadow. When another fracture encounters the stress shadow region of this fracture, its growth can be affected. Figure 6(a) shows a good example of multiple-fracture generation in a case where the stress shadow effect is significant. The propagation paths of the branch fractures are not planar but curved, revealing mutually exclusive propagation. This phenomenon has also been confirmed by other studies [31, 32].

Figure 6(a) illustrates the influence of the stress shadow on two hydraulic fractures propagating in a consistent direc-
TABle 2: Parameters used in the simulation of field-scale hydraulic fracture propagation with a preset slot.

\begin{tabular}{lcc}
\hline Material properties & Value & Unit \\
\hline Young's modulus & 5 & $\mathrm{GPa}$ \\
Poisson's ratio & 0.3 & - \\
Tensile strength & 1 & $\mathrm{MPa}$ \\
Injection rate & 1 & $\mathrm{~m}^{3} / \mathrm{min}$ \\
Viscosity & 1 & $\mathrm{cP}$ \\
\hline
\end{tabular}

tion. When the propagation directions of the two fractures are opposite, the influence of the stress shadow should be different. To study this effect, the same rock sample and loading 


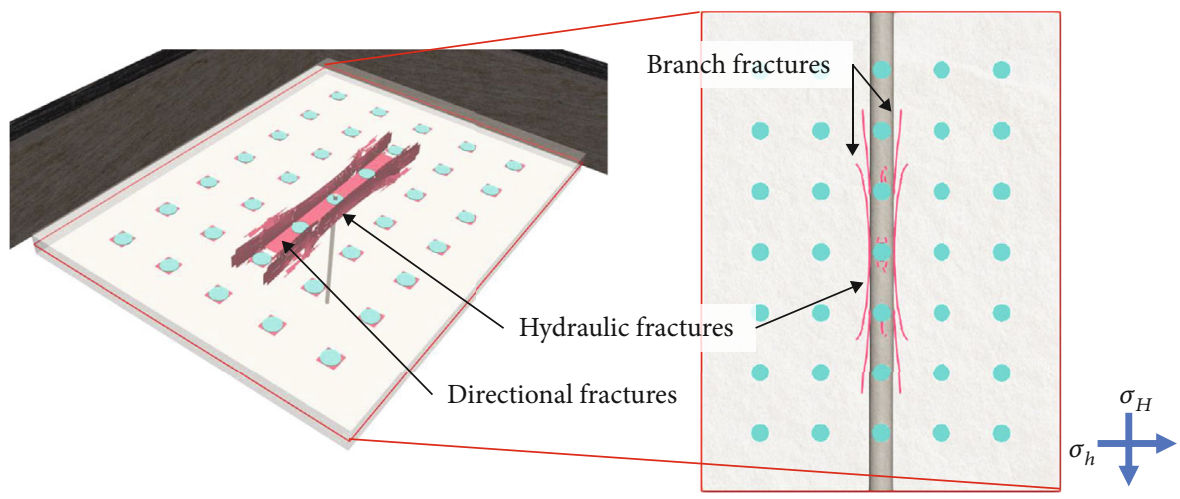

(a) With preset slots, $t=5 \mathrm{~min}$

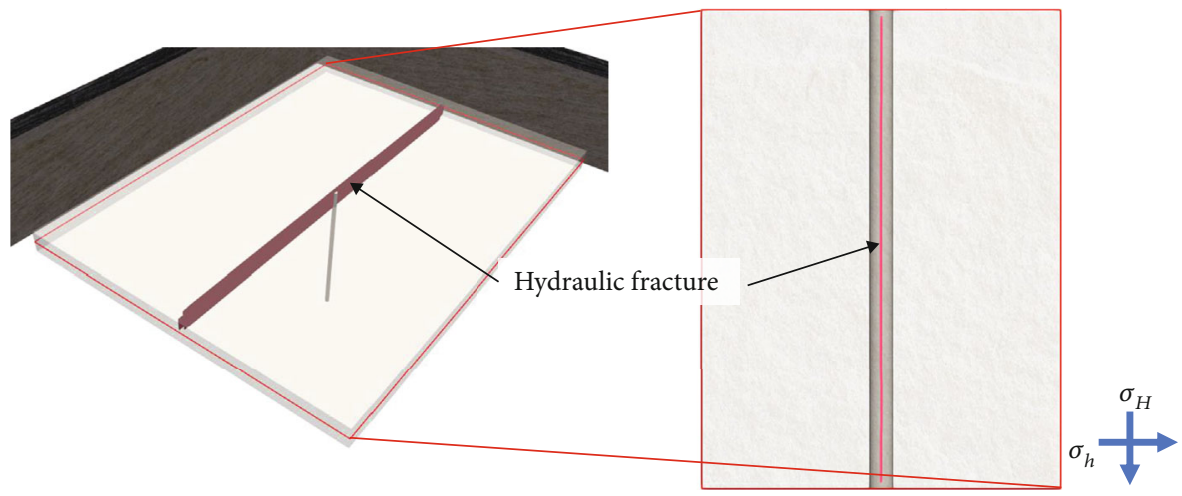

(b) Without preset slots, $t=5 \mathrm{~min}$

FIGURE 11: Comparison of hydraulic fracture patterns created by hydraulic fracturing (a) with and (b) without a regular distribution of hydraulic slots.

conditions used in Section 3.2 are adopted. Two half-slots are produced at two opposite sides of the sample (Figure 8 ). The spacing along the minimum horizontal stress direction is $8 \mathrm{~cm}$. In the simulation, the two slots are injected simultaneously at the same rate of $1.3 \mathrm{ml} / \mathrm{s}$. Two hydraulic fractures can be initialized and propagate in opposite directions. Figure 8 shows the pattern of the two fractures. The propagation paths are also spatially reoriented; however, these paths are not mutually exclusive but attractive. This effect is defined as fracture coalescence and has also been obtained in experimental observations $[43,44]$ and numerical results $[32,45]$.

\section{Integration of Multiple Hydraulic Slots and Hydraulic Fracturing in Field Applications}

4.1. Hydraulic Fracturing Combined with a Regular Distribution of Hydraulic Slots. According to the theoretical and numerical analyses in Sections 2 and 3, the preset slots have an impressive effect on the propagation pattern of the hydraulic fracture. Directional and branch fractures can be created by the use of preset slots, which enhances the complexity of the hydraulic fracture network; meanwhile, continuous fluid injection can extend the fracture network. Hydraulic slotting and hydraulic fracturing can be implemented successively through intense long cross boreholes in engineering practice to generate multislots (Figure 9) and multifractures.

To numerically study the hydraulic fracture pattern with integrated multiple hydraulic slots, a coal seam model was generated in FLAC3D (Figure 10) with dimensions of $80 \mathrm{~m}$ $\left(\sigma_{H}\right) \times 60 \mathrm{~m}\left(\sigma_{h}\right) \times 4 \mathrm{~m}\left(\sigma_{v}\right)$. Surrounding elements were added, and the integrated model was doubled in $\sigma_{H}$ direction and $\sigma_{h}$ directions to avoid the impact of a boundary effect during numerical calculation. Hydraulic slots with a radius of $1.5 \mathrm{~m}$ were created and regularly distributed in the coal seam at the same depth. In total, 5 (columns) $\times 7$ (rows) of hydraulic slots were preset, which were symmetric to the bottom roadway and had a slot spacing of $10 \mathrm{~m}$. The primary in situ stress [28] was adopted. It was related to the depth (equation (11)). In this study, we assumed that the coal seam was buried at a depth of $500 \mathrm{~m}$. Thus, the vertical stress was the intermediate principal stress $(13.5 \mathrm{MPa})$, and the maximum and minimum horizontal stresses were 14.3 and 10.6 $\mathrm{MPa}$, respectively. Water was designed to be directly injected into the central slots. The injection rate was constant and equal to $1 \mathrm{~m}^{3} / \mathrm{min}$. Other parameters used in the fieldscale simulation are listed in Table 2.

$$
\left\{\begin{array}{l}
\sigma_{v}=0.027 z, \\
\sigma_{H}=0.0268 z+0.8771, \\
\sigma_{h}=\frac{\sigma_{H}+0.6991}{1.4129},
\end{array}\right.
$$

where $z$ is the depth (m).

Figure 11 presents the result of a comparison of the hydraulic fracture patterns created by hydraulic fracturing 


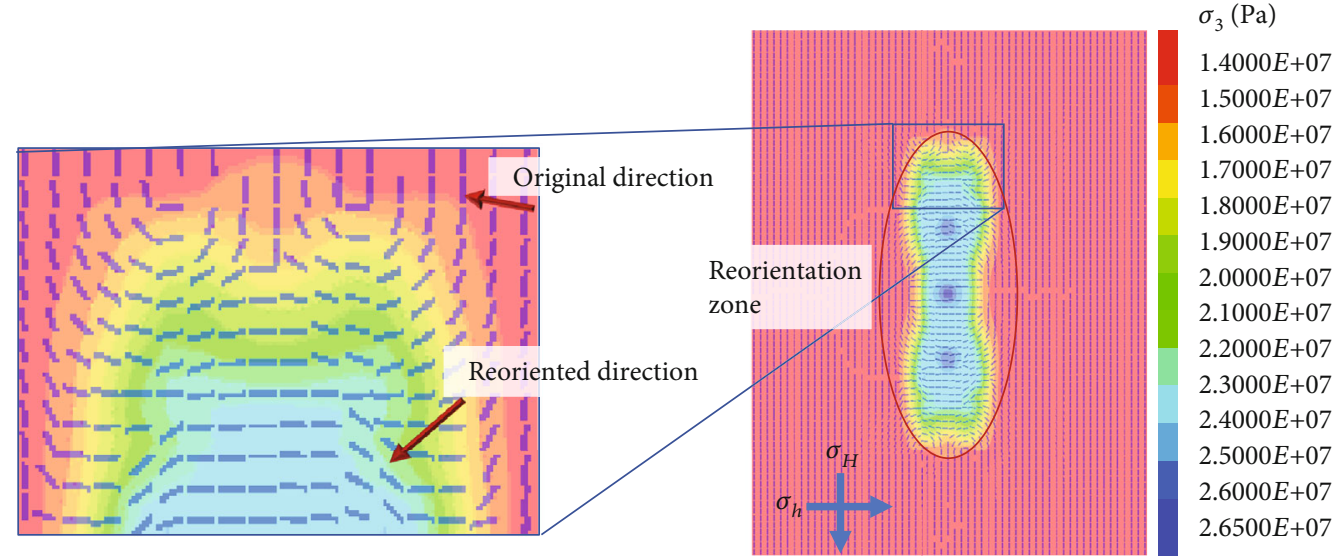

(a) With preset slots, $t=5 \mathrm{~min}$

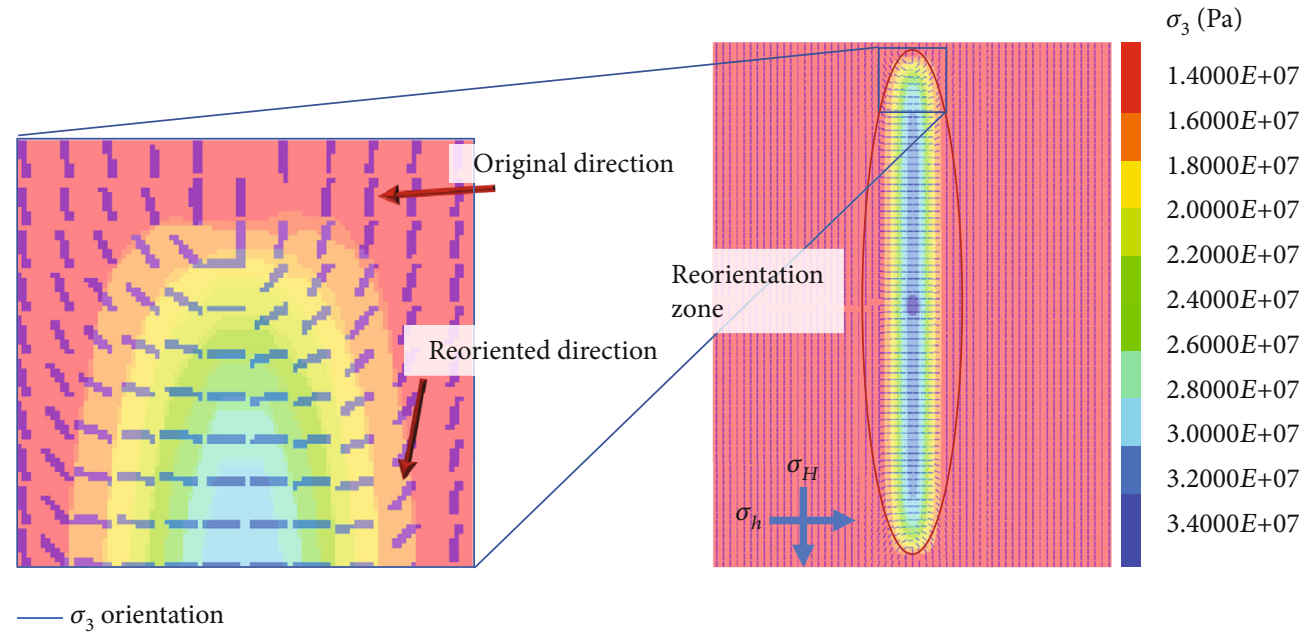

(b) Without preset slots, $t=5 \mathrm{~min}$

FIGURE 12: Stress distribution and orientation around hydraulic fractures (a) with and (b) without a regular distribution of hydraulic slots.

with the regular distribution of preset slots and without preset slots. Clearly, the hydraulic fracture pattern under the influence of the preset slots is more complex than that of a single hydraulic fracture without preset slots. A hydraulic fracture network (represented in red) was obtained. The fracture network consisted of directional fractures that were horizontally extended from the preset slots, and vertical branch fractures that were initialized from the preset slots and were approximately orthogonal to the minimum horizontal stress. Figure 12 illustrates the corresponding $\sigma_{3}$ state (magnitude and orientation) of Figure 11. Distinct reorientation of $\sigma_{3}$ appeared in both hydraulic fracturing with and without a regular distribution of hydraulic slots, while a wider stress affected region is formed in Figure 12(a) due to hydraulic slots, which could influence hydraulic fracture evolution and induce a sharper reorientation of branch fractures. According to the temporal development of the fracture network (Figure 13), two branch fractures were first initialized at the injection slot. Then, both directional fracture and branch fractures propagated at comparable speeds because the stress anisotropy was small. When the directional fracture met another preset slot, two more branch fractures were initialized that enhanced the fracture network complexity. However, the propagation direction of the generated fracture network was still governed by the in situ stress. Both directional fractures and branch fractures had their major propagation direction that were orthogonal to the minimum horizontal stress. Therefore, only the region parallel to the roadway was stimulated. Most preset slots made no contribution to enhancing the complexity and conductivity of the fracture network.

4.2. Hydraulic Fracturing Combined with a Staggered Distribution of Hydraulic Slots. According to the study in Section 4.1, the initialization of branch fractures from preset slots is a way to enhance the complexity of the fracture network. The main issue is to increase the number of hydraulic slots that can be intruded by hydraulic fractures. The basic idea is to place the hydraulic slots in the positions where the hydraulic fracture may approach. According to Figures 6 and 13, an exclusive propagation of the branch fractures initialized from a slot is obtained. The subsequent slots 


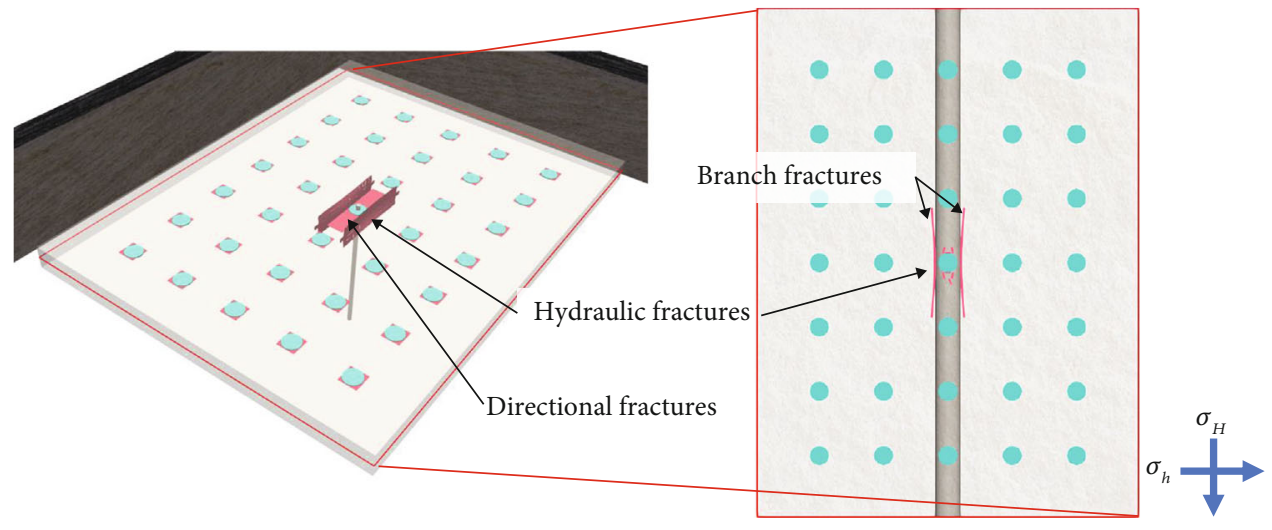

(a) $t=1 \mathrm{~min}$

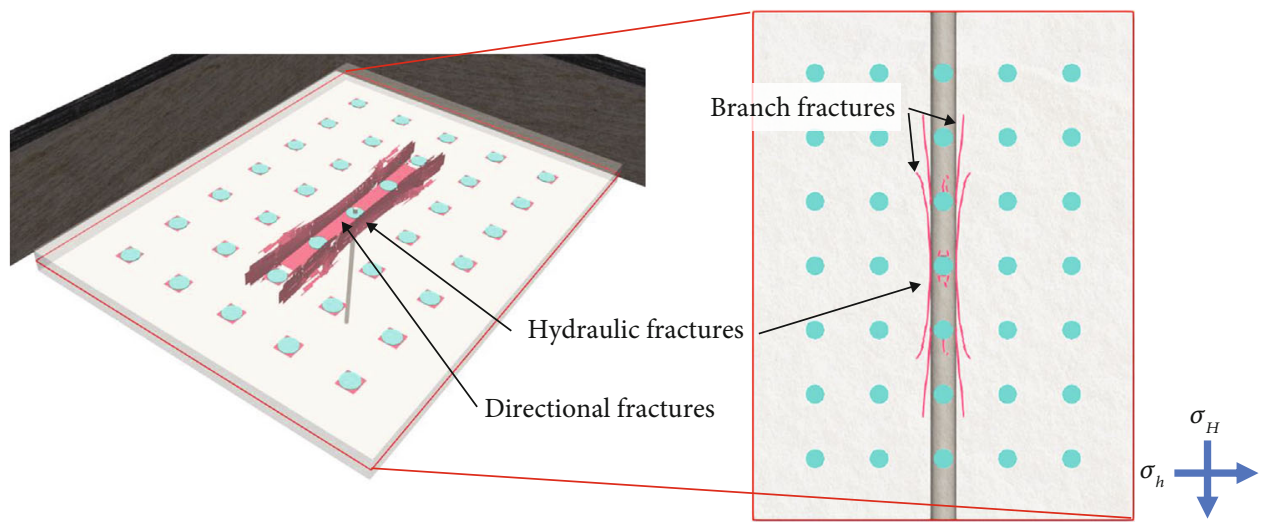

(b) $t=5 \mathrm{~min}$

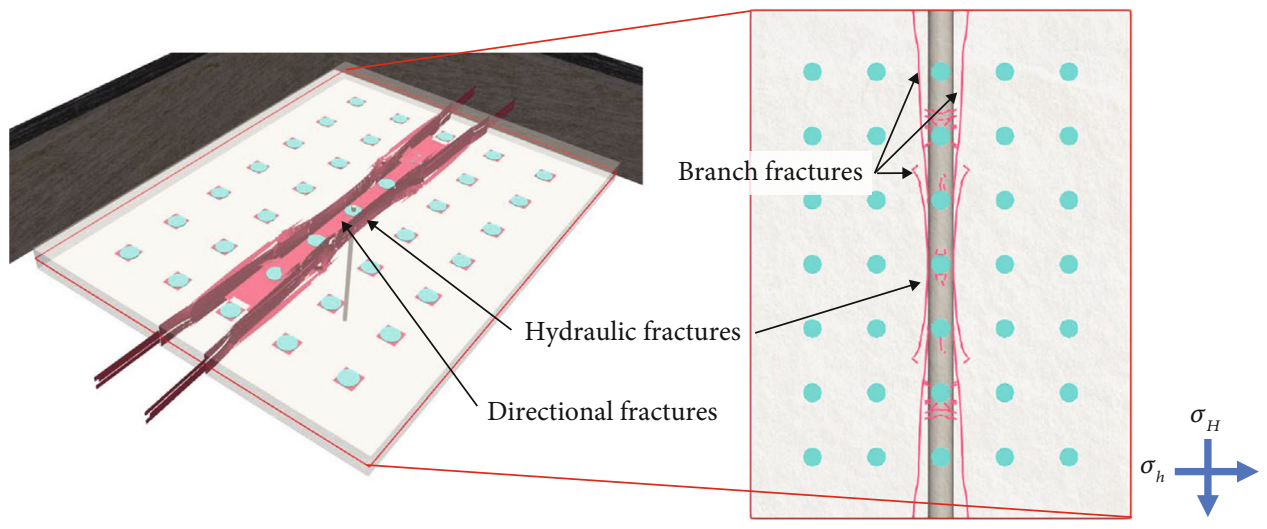

(c) $t=10 \mathrm{~min}$

FIGURE 13: Temporal development of the hydraulic fracture pattern created by hydraulic fracturing in combination with a regular distribution of hydraulic slots.

can be set on the propagation path of each branch fracture, revealing that the distribution of the preset slots should be in a staggered form. To prove the feasibility of the idea, a staggered distribution of the hydraulic slots was designed (Figure 14). The slot spacing of the preset slots in each row and the spacing between rows remained $10 \mathrm{~m}$. However, the preset slots in two neighbouring rows were set with a $5 \mathrm{~m}$ dislocation. The model geometry, the in situ stress, and the injection and physical parameters are given in Section 4.1.

Figure 15 shows the spatial morphologies of the hydraulic fracture at different injection times. Similar to the simulation with a regular distribution of the preset slots, the branch frac- tures were first initialized from the injection slot. Then, they propagated exclusively to the staggered preset slots in the subsequent rows. After the branch fractures met the subsequent preset slots, termination of the branch fractures by the preset slots was obtained, since the preset slots had significantly higher flow conductivity than the hydraulic fractures. Subsequently, the pressure increased in the preset slots until new branch fractures were initialized. Interestingly, the branch fractures generated at the outer side could propagate in the backward direction, which was advantageous to connect the preset slots in the previous row and again to create more branch fractures. The process of branch fracture 


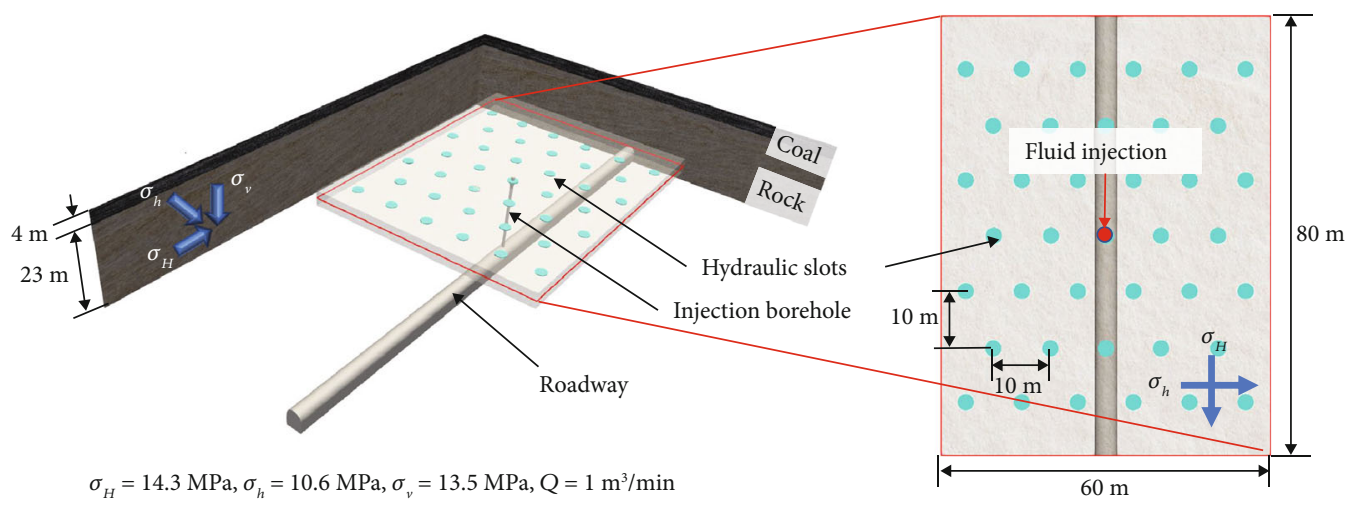

Figure 14: Geometric model and conditions for simulation of hydraulic fracturing in combination with a staggered distribution of hydraulic slots.

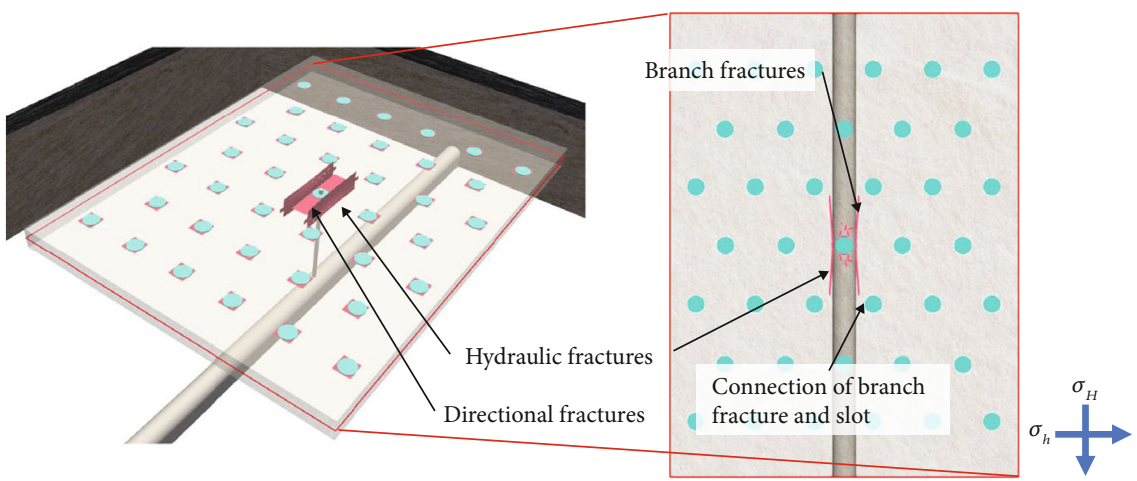

(a) $t=1 \mathrm{~min}$

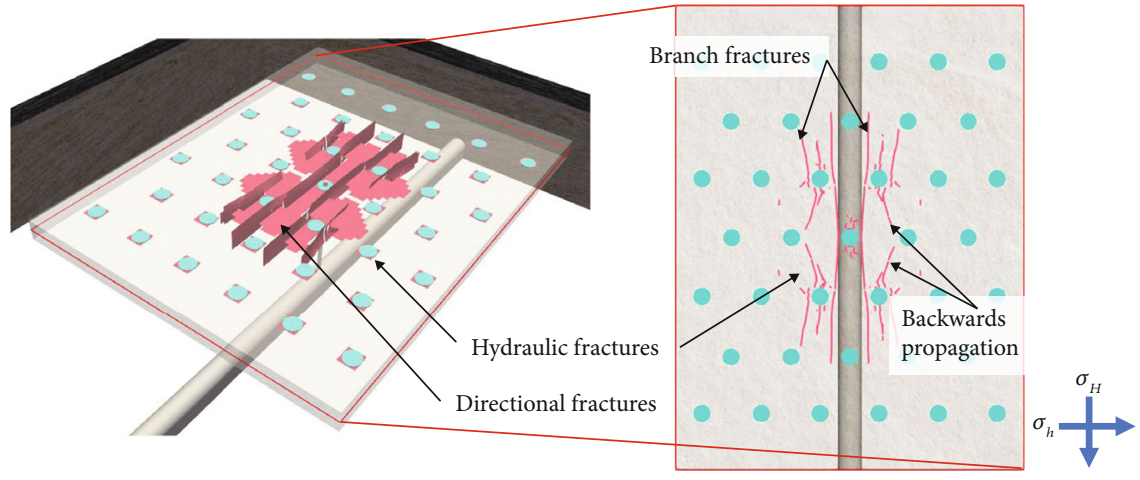

(b) $t=5 \mathrm{~min}$

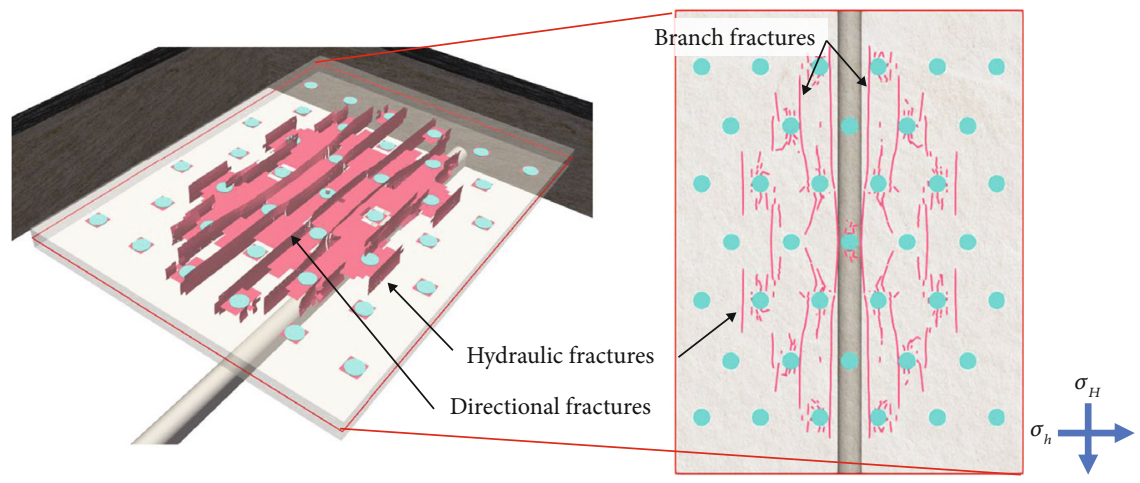

(c) $t=10 \mathrm{~min}$

FIGURE 15: Temporal development of the hydraulic fracture pattern created by hydraulic fracturing in combination with a staggered distribution of hydraulic slots. 


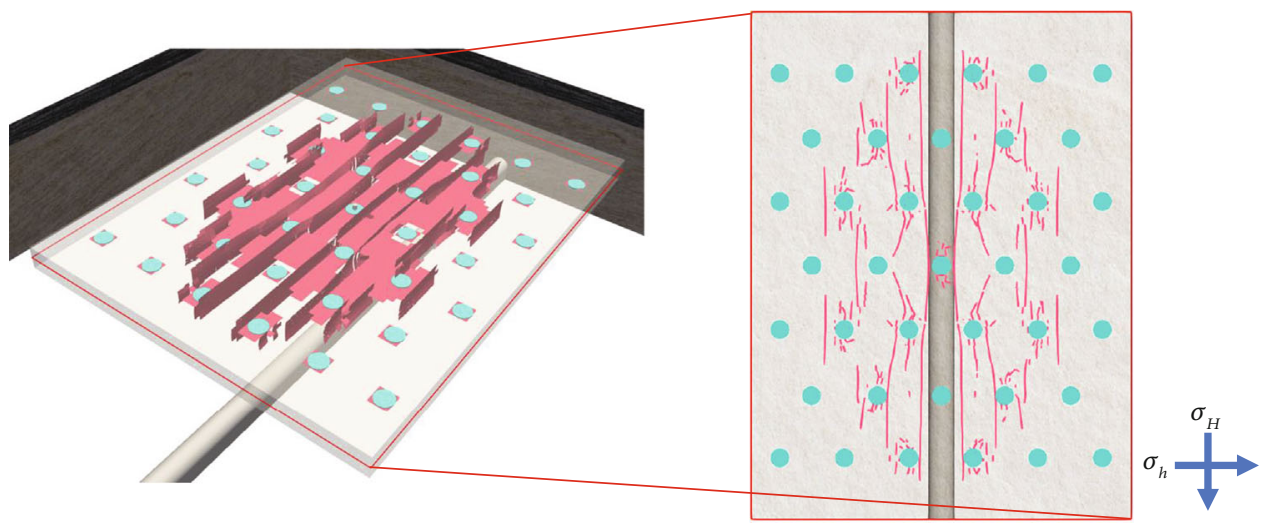

(a) $\sigma_{H}=14.3 \mathrm{MPa}, \sigma_{h}=10.6 \mathrm{MPa}, \sigma_{v}=13.5 \mathrm{MPa}, Q=1 \mathrm{~m}^{3} / \mathrm{min}, z=500 \mathrm{~m}$

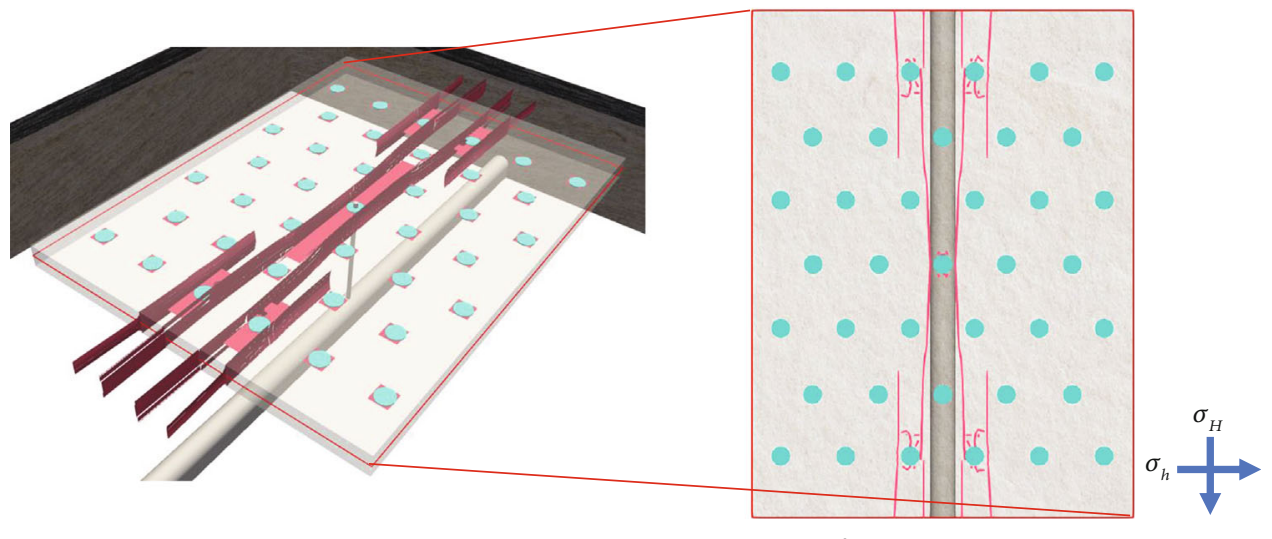

(b) $\sigma_{H}=27.6 \mathrm{MPa}, \sigma_{h}=20 \mathrm{MPa}, \sigma_{v}=27 \mathrm{MPa}, Q=1 \mathrm{~m}^{3} / \mathrm{min}, z=1000 \mathrm{~m}$

FIGURE 16: Comparison of hydraulic fracture patterns created by hydraulic fracturing in combination with a staggered distribution of hydraulic slots under (a) low stress difference and (b) high stress difference.

generation was similar to "nuclear fission." Branch fractures played the role of neutrons, while preset slots played the role of uranium nuclei. One branch fracture could initialize two branch fractures when it met a preset slot. In addition, the directional effect of the preset slots was improved since more preset slots were activated. Finally, a relatively large volume in both the minimum and maximum horizontal stress directions was stimulated, consisting of many vertical branch fractures and a large area of horizontally layered directional fractures. Therefore, hydraulic fracturing with a staggered distribution of preset slots can be concluded to generate a fracture network with higher complexity and to maximize the stimulated volume.

4.3. Discussion. The precondition to activate many preset slots is that the branch fractures can approach the subsequent preset slots. The induced stress shadow effect between the branch fractures can reorient the branch fractures that benefit the connection of the branch fractures and the preset slots. However, the reorientation effect caused by the stress shadow is strongly dependent on the stress anisotropy. As the mining depth increases, its stress anisotropy increases; e.g., at a depth of $1000 \mathrm{~m}$, the difference between the maximum and the minimum horizontal stress is $7.6 \mathrm{MPa}$ according to equation (11), which is doubled when compared with that at a depth of $500 \mathrm{~m}$. Figure 16 presents a result of a comparison of the hydraulic fracture patterns considering low and high stress differences. The reduced reorientation effect caused by the high stress difference is obvious. Branch fractures initialized from the injection slot cannot approach the preset slots in the subsequent row, although the staggered distribution of the preset slots was applied. To improve the connection between the branch fractures and the preset slots, two major factors can be considered. One factor is increasing the reorientation effect of the branch fractures, e.g., using a high injection rate and simultaneous injection in multiple preset slots. The other factor is increasing the influence range of the preset slots, e.g., reducing the slot spacing and increasing the slot radius.

\section{Conclusion}

In this paper, the stress field around a pressurized fracture, the effects of preset slots, and induced stress shadows on hydraulic fracture propagation were theoretically and numerically analysed. Based on the principle of branch fracture generation and the competitive propagation phenomenon of multiple hydraulic fractures, we proposed a novel method to create a complex hydraulic fracture network in underground coal mines with the integration of hydraulic technologies including staggered distributed multiple slotting 
and fracturing. According to the study, the following conclusions were obtained:

(1) The propagation reorientation effect by a preset slot is affected by the deviation angle, the internal fluid pressure, and the in situ stress, and can be categorized as controlled by fluid pressure, by both internal fluid pressure and stress, or by stress. The dynamically induced stress shadows of hydraulic fractures can cause exclusive and attractive propagation of multiple hydraulic fractures

(2) A preset slot that deviates from the principal stress can direct the hydraulic fracture to a certain extent; however, the primary stress field is still the major factor controlling the fracture propagation, particularly in a situation where the fracture propagates far from the slot

(3) A preset slot can be considered a partially cracked or nonpersistent natural fracture that can first arrest the hydraulic fracture and then interact via fracture branching, fracture crossing, or both fracture branching and crossing. Branch fractures can be initialized by the large deviation angle of a preset slot

(4) The integration of hydraulic fracturing and multiple preset slots with a staggered distribution can stimulate a relatively large volume in both the minimum and maximum horizontal stress directions, creating a fracture network with higher complexity including many vertical branch fractures and a large area of horizontally layered directional fractures

\section{Data Availability}

All the original data and analysed data used to support the findings of this study are included within the article.

\section{Conflicts of Interest}

The authors declare that there are no conflicts of interest regarding the publication of this paper.

\section{Acknowledgments}

The work presented in this paper is funded by the National Science Fund for Distinguished Young Scholars of China (No. 51625401), the National Natural Science Foundation of China (Nos. U19B2009 and 51774056), the Chongqing Research Program of Basic Research and Frontier Technology (No. CSTC2017JCYJB0252), and the Program for Changjiang Scholars and Innovative Research Team in University (IRT_17R112).

\section{References}

[1] D. Spencer, "BP statistical review of world energy statistical review of world," in The Editor BP Statistical Review of World Energy, pp. 1-69, BP Statistical Review, London, UK, 2019.
[2] F. Zhou, T. Xia, X. Wang, Y. Zhang, Y. Sun, and J. Liu, "Recent developments in coal mine methane extraction and utilization in China: a review," Journal of Natural Gas Science and Engineering, vol. 31, pp. 437-458, 2016.

[3] China, Ministry of Emergency Management, Safety Regulations of Coal Mine, 2016.

[4] L. Zhang, C. Zhang, S. Tu, H. Tu, and C. Wang, "A study of directional permeability and gas injection to flush coal seam gas testing apparatus and method," Transport in Porous Media, vol. 111, no. 3, pp. 573-589, 2016.

[5] C. J. Zhu, J. Ren, J. M. Wan, B. Q. Lin, K. Yang, and Y. Li, "Methane adsorption on coals with different coal rank under elevated temperature and pressure," Fuel, vol. 254, article 115686, 2019.

[6] K. H. Sampath, M. S. Perera, P. G. Ranjith et al., " $\mathrm{CH}_{4}-\mathrm{CO}_{2}$ gas exchange and supercritical $\mathrm{CO}_{2}$ based hydraulic fracturing as CBM production-accelerating techniques: a review," Journal of CO2 Utilization, vol. 22, pp. 212-230, 2017.

[7] X. H. Li, Y. Y. Lu, Y. Zhao, Y. Kang, and D. P. Zhou, "Study on improving the permeability of soft coal seam with high pressure pulsed water jet," Journal of China Coal Society, vol. 33, no. 12, pp. 1386-1390, 2008.

[8] G. Y. Si, S. Durucan, J. Q. Shi, A. Korre, and W. Z. Cao, "Parametric analysis of slotting operation induced failure zones to stimulate low permeability coal seams," Rock Mechanics and Rock Engineering, vol. 52, no. 1, pp. 153-182, 2019.

[9] Y. Y. Lu, Y. Liu, X. H. Li, and Y. Kang, "A New method of drilling long boreholes in low permeability coal by improving its permeability," International Journal of Coal Geology, vol. 84, no. 2, pp. 94-102, 2010.

[10] B. Lin, F. Yan, C. Zhu et al., "Cross-borehole hydraulic slotting technique for preventing and controlling coal and gas outbursts during coal roadway excavation," Journal of Natural Gas Science and Engineering, vol. 26, pp. 518-525, 2015.

[11] J. Xie, Y. P. Liang, Q. L. Zhou, L. Li, and X. L. Li, "Elimination of coal and gas outburst risk of low-permeability coal seam using high-pressure water jet slotting technology: a case study in Shihuatian Coal Mine in Guizhou Province, China," Energy Science and Engineering, vol. 7, no. 4, pp. 1394-1404, 2019.

[12] S. J. Zou, Z. L. Ge, Z. Zhou, L. Wang, and H. Y. Zhao, “A novel hydraulic mode to promote gas extraction: pressure relief technologies for tectonic regions and fracturing technologies for nontectonic regions," Applied Sciences, vol. 9, no. 7, 2019.

[13] B. Q. Lin, J. G. Zhang, C. M. Shen, Q. Z. Zhang, and C. Sun, "Technology and application of pressure relief and permeability increase by jointly drilling and slotting coal," International Journal of Mining Science and Technology, vol. 22, no. 4, pp. 545-551, 2012.

[14] M. Economides and K. G. Nolte, Reservior Stimulation, vol. 18, Wiley, 2013.

[15] Z. Jiang, Q. Li, Q. Hu et al., "Underground microseismic monitoring of a hydraulic fracturing operation for CBM reservoirs in a coal mine," Energy Science and Engineering, vol. 7, no. 3, pp. 986-999, 2019.

[16] S. P. Huang, D. M. Liu, Y. B. Yao, Q. Gan, Y. D. Cai, and L. L. $\mathrm{Xu}$, "Natural fractures initiation and fracture type prediction in coal reservoir under different in-situ stresses during hydraulic fracturing," Journal of Natural Gas Science and Engineering, vol. 43, pp. 69-80, 2017.

[17] T. T. Jiang, J. H. Zhang, and H. Wu, "Experimental and numerical study on hydraulic fracture propagation in coalbed 
methane reservoir," Journal of Natural Gas Science and Engineering, vol. 35, pp. 455-467, 2016.

[18] X. Sun, S. C. Zhang, X. F. Ma, Y. S. Zou, and G. Y. Lin, "Experimental investigation on propagation behavior of hydraulic fractures in coal seam during refracturing," Geofluids, vol. 2019, 15 pages, 2019.

[19] C. F. Wu, X. Y. Zhang, M. Wang, L. G. Zhou, and W. Jiang, "Physical simulation study on the hydraulic fracture propagation of coalbed methane well," Journal of Applied Geophysics, vol. 150, pp. 244-253, 2018.

[20] Z. R. Chen, R. G. Jefferey, X. Zhang, and C. E. Flagship, "Numerical modeling of three-dimensional T-shaped hydraulic fractures in coal seams using a cohesive zone finite element model," Hydraulic Fracturing Journal, vol. 2, no. 2, 2015.

[21] L. Zhou, X. P. Su, Y. Y. Lu, Z. L. Ge, Z. Y. Zhang, and Z. H. Shen, "A new three-dimensional numerical model based on the equivalent continuum method to simulate hydraulic fracture propagation in an underground coal mine," Rock Mechanics and Rock Engineering, vol. 52, no. 8, pp. 28712887, 2019.

[22] J. P. Zou, W. Z. Chen, J. Q. Yuan, D. S. Yang, and J. P. Yang, "3-D numerical simulation of hydraulic fracturing in a CBM reservoir," Journal of Natural Gas Science and Engineering, vol. 37, pp. 386-396, 2017.

[23] Y. G. Cheng, Y. Y. Lu, Z. L. Ge, L. Cheng, J. W. Zheng, and W. F. Zhang, "Experimental study on crack propagation control and mechanism analysis of directional hydraulic fracturing," Fuel, vol. 218, pp. 316-324, 2018.

[24] J. Q. Deng, C. Lin, Q. Yang, Y. R. Liu, Z. F. Tao, and H. F. Duan, "Investigation of directional hydraulic fracturing based on true tri-axial experiment and finite element modeling," Computers and Geotechnics, vol. 75, pp. 28-47, 2016.

[25] R. B. Mao, Z. J. Feng, Z. H. Liu, and Y. S. Zhao, "Laboratory hydraulic fracturing test on large-scale pre-cracked granite specimens," Journal of Natural Gas Science and Engineering, vol. 44, pp. 278-286, 2017.

[26] Y. Liu, B. W. Xia, and X. T. Liu, "A novel method of orienting hydraulic fractures in coal mines and its mechanism of intensified conduction," Journal of Natural Gas Science and Engineering, vol. 27, pp. 190-199, 2015.

[27] F. Yan, B. Lin, C. Zhu et al., "A novel ECBM extraction technology based on the integration of hydraulic slotting and hydraulic fracturing," Journal of Natural Gas Science and Engineering, vol. 22, pp. 571-579, 2015.

[28] S. Chen, D. Tang, S. Tao et al., "In-situ stress measurements and stress distribution characteristics of coal reservoirs in major coalfields in China: implication for coalbed methane (CBM) development," International Journal of Coal Geology, vol. 182, pp. 66-84, 2017.

[29] A. E. Green and I. N. Sneddon, "The distribution of stress in the neighbourhood of a flat elliptical crack in an elastic solid," Mathematical Proceedings of the Cambridge Philosophical Society, vol. 46, no. 1, pp. 159-163, 1950.

[30] L. Zhou and M. Z. Hou, "A new numerical 3D-model for simulation of hydraulic fracturing in consideration of hydromechanical coupling effects," International Journal of Rock Mechanics and Mining Sciences, vol. 60, pp. 370-380, 2013.

[31] A. P. Bunger, R. G. Jefferey, J. Kear, X. Zhang, and M. Morgan, "Experimental investigation of the interaction among closely spaced hydraulic fractures," 45th US Rock Mechanics/Geomechanics Symposium, 2011.
[32] X. Y. Ren, L. Zhou, H. L. Li, and Y. Y. Lu, "A threedimensional numerical investigation of the propagation path of a two-cluster fracture system in horizontal wells," Journal of Petroleum Science and Engineering, vol. 173, pp. 12221235, 2019.

[33] A. I. Lurie and A. Belyaev, Theory of Elasticity, Springer, Berlin Heidelberg, 2005.

[34] I. N. Sneddon and H. A. Elliot, "The opening of a Griffith crack under internal pressure," Quarterly of Applied Mathematics, vol. 4, no. 3, pp. 262-267, 1946.

[35] F. Erdogan and G. C. Sih, "On the crack extension in plates under plane loading and transverse shear," Journal of Basic Engineering, vol. 85, no. 4, pp. 519-525, 1963.

[36] R. W. Zimmerman and S. G. Bodvarsson, "Hydraulic conductivity of rock fractures," Transport in Porous Media, vol. 23, no. 1, pp. 1-30, 1996.

[37] Y. N. Yang, X. Y. Ren, L. Zhou, and Y. Y. Lu, "Numerical study on competitive propagation of multi-perforation fractures considering full hydro-mechanical coupling in fracture-pore dual systems," Journal of Petroleum Science and Engineering, vol. 191, article 107109, 2020.

[38] W. Fu, B. C. Ames, A. P. Andrew, and A. A. Savitski, "Impact of partially cemented and non-persistent natural fractures on hydraulic fracture propagation," Rock Mechanics and Rock Engineering, vol. 49, no. 11, pp. 4519-4526, 2016.

[39] R. V. Goldstein and N. M. Osipenko, "Initiation of a secondary crack across a frictional interface," Engineering Fracture Mechanics, vol. 140, pp. 92-105, 2015.

[40] Y. L. Jiang, H. J. Liao, V. P. Nguyen, and W. G. Liang, "Propagation behavior of hydraulic fracture across the coal-rock interface under different interfacial friction coefficients and a new prediction model," Journal of Natural Gas Science and Engineering, vol. 68, article 102894, 2019.

[41] H. Ouchi, J. T. Foster, and M. M. Sharma, "Effect of reservoir heterogeneity on the vertical migration of hydraulic fractures," Journal of Petroleum Science and Engineering, vol. 151, pp. 384-408, 2017.

[42] W. J. Xu, J. Z. Zhao, S. S. Rahman, Y. M. Li, and Y. D. Yuan, “A comprehensive model of a hydraulic fracture interacting with a natural fracture: analytical and numerical solution," Rock Mechanics and Rock Engineering, vol. 52, no. 4, pp. 1095$1113,2019$.

[43] Y. H. Huang, S. Q. Yang, and W. L. Tian, "Crack coalescence behavior of sandstone specimen containing two pre-existing flaws under different confining pressures," Theoretical and Applied Fracture Mechanics, vol. 99, pp. 118-130, 2019.

[44] S. Q. Yang, P. F. Yin, Y. C. Zhang et al., "Failure behavior and crack evolution mechanism of a non-persistent jointed rock mass containing a circular hole," International Journal of Rock Mechanics and Mining Sciences, vol. 114, pp. 101-121, 2019.

[45] B. Paul, M. Faivre, P. Massin et al., "3D coupled HM-XFEM modeling with cohesive zone model and applications to non planar hydraulic fracture propagation and multiple hydraulic fractures interference," Computer Methods in Applied Mechanics and Engineering, vol. 342, pp. 321-353, 2018. 